\title{
A Reconsideration of Money Growth Rules
}

\author{
Michael T. Belongia* \\ University of Mississippi \\ Peter N. Ireland ${ }^{\dagger}$ \\ Boston College
}

March 2019

\begin{abstract}
A New Keynesian model, estimated using Bayesian methods over a sample period that includes the recent episode of zero nominal interest rates, illustrates the effects of replacing the Federal Reserve's historical policy of interest rate management with one targeting money growth instead. Counterfactual simulations show that a rule for adjusting the money growth rate, modestly and gradually, in response to changes in the output gap delivers performance comparable to the estimated interest rate rule in stabilizing output and inflation. The simulations also reveal that, under the same money growth rule, the US economy would have recovered more quickly from the 200709 recession, with a much shorter period of exceptionally low interest rates. These results suggest that money growth rules can serve as a simple and effective alternative guide for monetary policy in the current low interest rate environment.
\end{abstract}

JEL Codes: E31, E32, E41, E47, E51, E52.

Keywords: Divisia monetary aggregates, Monetary policy rules, New Keynesian models, Zero lower bound.

${ }^{*}$ Michael T. Belongia, Department of Economics, University of Mississippi, Box 1848, University, MS 38677. Email: mvpt@earthlink.net.

${ }^{\dagger}$ Peter N. Ireland, Department of Economics, Boston College, 140 Commonwealth Avenue, Chestnut Hill MA 02467. Email: peter.ireland@bc.edu. Web: https://www2.bc.edu/peter-ireland. 


\section{Introduction}

For the past quarter century, and perhaps longer, the Federal Reserve has conducted monetary policy by managing nominal interest rates. While today's practice of strict federal funds rate targeting has its origins in the early 1990s, Greenspan (1997), Meulendyke (1998), and Thornton (2007) all describe Federal Reserve policy as shifting towards tighter interest rate control beginning sometime in the 1980s. Cook (1989) goes back even further, arguing that the reserves targeting procedures used from 1979 through 1982 disguised policy actions taken to manage the funds rate instead.

Academic economists also depict Federal Reserve policy as managing interest rates. Taylor (1993) introduced his now-famous rule, which describes how the Fed adjusts its interest rate target in response to movements in the output gap and inflation. Taylor (1993) also demonstrates that the strikingly simple formula tracks actual movements in the federal funds rate remarkably well over the period from 1987 through 1992. Some variant of the Taylor rule now appears as the description of monetary policy in textbook New Keynesian models presented, for example, by Woodford (2003) and Galí (2015).

Preference for interest rate management, in both practice and theory, often is motivated with reference to Poole's (1970) classic analysis, demonstrating that in a stochastic IS-LM model, policies targeting the nominal interest rate insulate output from the effects of money demand shocks, whereas policies targeting the money stock instead allow these shocks to contribute to macroeconomic volatility. Poole's model holds the aggregate price level fixed, but Ireland (2000), Collard and Dellas (2005), and Galí (2015) demonstrate that these results extend to modern New Keynesian models as well, in which monetary policies calling for a constant rate of money growth lead to excess volatility in both output and inflation,

compared to policies targeting interest rates instead, especially when the economy is hit by recurrent money demand shocks. Furthermore, as emphasized by Ireland (2004b) and Belongia and Ireland (2018b), standard New Keynesian models feature forward-looking variants of more traditional Keynesian IS and Phillips curve that imply monetary policy affects out- 
put and inflation exclusively through its ability to influence the current and expected future path for the short-term nominal interest rate. The Taylor rule, therefore, becomes a natural benchmark for describing monetary policy in these models. And, to the extent that Federal Reserve officials also believe that monetary policy influences economic activity mainly if not entirely through the New Keynesian interest rate channel, it makes sense for them to focus on managing interest rates as well.

Recent events, however, prompt a reconsideration of the prevailing consensus favoring interest rate rules. First and most obviously, the extended period from 2009 through 2015, during which the Federal Reserve's traditional federal funds rate targeting procedures were constrained by the perceived lower bound on nominal interest rates, raises the question of whether alternative policy rules focused on managing the money stock might have allowed the Fed to pursue its stabilization objectives more effectively during and after the financial crisis and Great Recession of 2007-09. Belongia and Ireland (2017, 2018a) present empirical evidence suggesting that this may have been the case, but stop short of exploring the possibility, theoretically, in the standard New Keynesian framework. Second, the Fed's actual response to continued weakness in output and inflation while the funds rate remained in a target range near zero went beyond three waves of large-scale asset purchases. Also required were other important changes in operating procedures, such as the introduction of interest payments on bank reserves and the establishment of a reverse repurchase agreement program through which the Fed interacted with a wide range of nonbank financial institutions. Although moving from a policy involving interest rate management to one of targeting the growth rate of a monetary aggregate might once have seemed prohibitively difficult, this recent experience shows, to the contrary, that operating procedures and institutional arrangements can be changed significantly, even on short notice, to support any major shift in policy regime. Finally, while the previous studies by Ireland (2000), Collard and Dellas (2005), and Galí (2015) all suggest that policy rules calling for constant rates of money growth will perform poorly, relative to Taylor rules, in stabilizing output and inflation, none 
of these studies considers the possibility that money growth rules might work significantly better if they allowed policy to adjust to movements in the output gap and inflation in a manner similar to that of the Taylor rule.

Thus, this paper extends previous work by reconsidering money growth rules in an estimated New Keynesian model. By identifying a parsimonious rule that dictates a systematic response of money growth to changes in the output gap, it follows in the same style of research presented, for instance, in Taylor (1999) by characterizing rules that remain simple while still delivering favorable economic outcomes. And by using counterfactual simulations to assess how the US economy would have performed over a sample period running from 1983 through 2018, it illustrates the satisfactory performance of a money growth rule in both good times - the period of the Great Moderation - and bad - the Great Recession and its aftermath.

The particular variant of the New Keynesian model used here takes most of its basic features from those in Ireland $(2004 a, 2004 b, 2007,2011)$, but innovates in four distinct ways. First, it introduces real money balances into a representative household's utility function in a manner that leaves the New Keynesian IS and Phillips curves in their standard forms, excluding the additional terms involving money growth that appear in Ireland (2004b). This ensures that the extended model retains the New Keynesian assumption that monetary policy actions have an impact on output and inflation only through their effects on the current and expected future path of the short-term nominal interest rate. The intent is to put money growth rules to a most stringent test, by excluding model features that might specifically favor stability in the money stock.

Second, the model's money-in-the-utility function specification is also tailored to imply that the level of real balances demanded by the non-bank public remains finite even as nominal interest rates fall to zero, reflecting observations made by Ireland (2009) and Rognlie (2016) that US money demand did not explode during either episode of very low nominal interest rates following the last two recessions. Intriguingly, as noted by Roglie (2016), this 
specification implies that short-term interest rates can fall below zero, at least by modest amounts for short periods of time, in a well-defined equilibrium - a phenomenon that will be explored in the counterfactual experiments performed with the estimated model. ${ }^{1}$ Third, the model includes adjustment costs of real balances in its specification, following Nelson (2002) and Andrés, López-Salido, and Nelson (2004, 2009), all of which present evidence that New Keynesian models with money fit the data better when they allow for gradual adjustment of real balances to shocks that hit the economy.

Fourth and finally, the analysis here employs methods developed by Kulish, Morley, and Robinson (2017) to account for periods, like that experienced in the US from 2009 through 2015, when short-term nominal interest rates were constrained by the central bank to remain near zero. According to the New Keynesian model, even after its current policy rate is lowered to zero, the central bank can use "forward guidance," in the form of policy announcements that lengthen private agents' expectations regarding the duration of the zero interest rate episode, to deliver additional monetary stimulus. The Bayesian estimation methods used here exploit survey data to track changes in the expected duration of the zero interest rate period and the effects these shifts in expectations have on output and inflation. Thus, with these methods, the model can be estimated over a sample running continuously from 1983 through 2018, accounting for the effects of both zero interest rates and forward guidance over the 2009-15 period as well as the effects of more traditional interest rate policy before and after. The estimated model can then be used to explore counterfactual scenarios in which the central bank systematically adjusts its target for the money growth rate under both favorable and unfavorable economic conditions.

The results from this exercise reveal that, even in a model that departs minimally from standard New Keynesian specifications and therefore offers no special role for changes in

\footnotetext{
${ }^{1}$ Recently, negative policy rates have been implemented by interest rate targeting central banks in Denmark, the Euro Area, Japan, Sweden, and Switzerland. The Swiss National Bank, in particular, has held its key policy rate at -0.75 percent since 2015. See Jackson (2015) for a discussion of the international experience with negative policy rates and Dong and Wen (2017) for another theoretical model that allows for negative nominal interest rates.
} 
the money stock, a money growth rule nonetheless can deliver performance on par with that generated by more conventional Taylor rules for the interest rate. The counterfactual simulations show, in particular, that under a money growth rule that responds modestly but persistently to changes in the output gap, the US economy would have recovered more quickly than it actually did from the financial crisis and Great Recession, without requiring a prolonged period of zero or negative interest rates. Thus, the results suggest that as Federal Reserve officials search for a new policy framework within which they can more reliably achieve their stabilization objectives in an environment of low interest rates and inflation following a series of adverse disturbances, abandoning the traditional practice of managing the federal funds rate in favor of a rule targeting the money growth rate should be added to the list of possibilities considered.

\section{The Model}

\subsection{Overview}

The model economy consists of a representative household, a representative finished goodsproducing firm, a continuum of intermediate goods-producing firms indexed by $i \in[0,1]$, and a central bank. During each period $t=0,1,2, \ldots$, each intermediate goods-producing firm produces a distinct intermediate good. Hence, intermediate goods are also indexed by

$i \in[0,1]$, with good $i$ produced by firm $i$. The model features enough symmetry, however, to allow the analysis to focus on the behavior of a representative intermediate goods-producing firm that manufactures the generic intermediate good $i$.

Habit formation introduced through the representative household's preferences and incomplete indexation of sticky nominal goods prices set by monopolistically competitive intermediate goods-producing firms imply that the model's New Keynesian IS and Phillips curves include both backward and forward-looking elements. The estimation procedure allows the data to decide on the relative importance of these backward and forward-looking 
terms. The central bank in the estimated model conducts monetary policy according to a version of the Taylor (1993) rule, reflecting the Federal Reserve's actual practice of federal funds rate targeting over most if not all of the 1983-2018 sample period. ${ }^{2}$ As noted above, however, the introduction of a money demand curve of a form that is consistent with the same US data also permits consideration of counterfactual monetary policy rules for money growth targeting instead.

\subsection{The Representative Household}

The representative household enters each period $t=0,1,2, \ldots$ with $M_{t-1}$ units of money and $B_{t-1}$ bonds. At the beginning of period $t$, the household receives a lump-sum monetary transfer $T_{t}$ from the central bank. In addition, the household's bonds mature, yielding $B_{t-1}$ additional units of money. The household uses some of this money to purchase $B_{t}$ new bonds at the price of $1 / r_{t}$ units of money per bond; thus, $r_{t}$ denotes the gross nominal interest rate between $t$ and $t+1$.

During period $t$, the household supplies $h_{t}(i)$ units of labor to each intermediate goodsproducing firm $i \in[0,1]$. The household gets paid at the nominal wage rate $W_{t}$, earning $W_{t} h_{t}$ in labor income, where

$$
h_{t}=\int_{0}^{1} h_{t}(i) \mathrm{d} i
$$

denotes total hours worked during the period. Also during period $t$, the household consumes $C_{t}$ units of the finished good, purchased at the nominal price $P_{t}$ from the representative finished goods-producing firm.

At the end of period $t$, the household receives nominal profits $D_{t}(i)$ from each intermediate goods-producing frm $i \in[0,1]$. The household then carries $M_{t}$ units of money into period

\footnotetext{
${ }^{2}$ The Federal Reserve has never announced an explicit rule to guide the setting of its interest rate target. Nevertheless, the analysis here adopts the assumption made throughout the literature on New Keynesian economics that, empirically, changes in the federal funds rate target can be described accurately by a rule of the form originally proposed by Taylor (1993). Belongia and Ireland (2019b) use Greenbook data on the Fed's internal forecasts of output and inflation to characterize more sharply the mixture of discretion and rule-like behavior revealed by changes in the federal funds rate target since the 1980s.
} 
$t+1$, chosen subject to the budget constraint

$$
\frac{M_{t-1}+T_{t}+B_{t-1}+W_{t} h_{t}+D_{t}}{P_{t}} \geq C_{t}+\frac{M_{t}+B_{t} / r_{t}}{P_{t}}
$$

for all $t=0,1,2, \ldots$, where

$$
D_{t}=\int_{0}^{1} D_{t}(i) \mathrm{d} i
$$

denotes total profits received for the period.

The household's preferences are described by the expected utility function

$$
E_{0} \sum_{t=0}^{\infty} \beta^{t} a_{t}\left[\ln \left(C_{t}-\gamma C_{t-1}\right)+v\left(\frac{M_{t}}{P_{t} Z_{t}}, u_{t}\right)-\frac{\phi_{m}}{2}\left(\frac{M_{t} / P_{t}}{z M_{t-1} / P_{t-1}}-1\right)^{2}\left(\frac{M_{t}}{P_{t} Z_{t}}\right)-h_{t}\right] .
$$

where both the discount factor and the habit formation parameter lie between zero and one, with $0<\beta<1$ and $0 \leq \gamma \leq 1$. The preference shock $a_{t}$ follows the stationary autoregressive process

$$
\ln \left(a_{t}\right)=\rho_{a} \ln \left(a_{t-1}\right)+\varepsilon_{a t}
$$

for all $t=0,1,2, \ldots$, with $0 \leq \rho_{a}<1$, where the serially uncorrelated innovation $\varepsilon_{a t}$ is normally distributed with mean zero and standard deviation $\sigma_{a}$. Utility is additively separable across consumption, real balances, and hours worked so as to imply a specification for the model's IS curve that does not include terms involving money and employment. As shown by King, Plosser, and Rebelo (1988), additive separability also implies that a logarithmic specification over consumption is needed for the model to be consistent with balanced growth. Also for balanced growth, real balances $M_{t} / P_{t}$ enter utility through the function $v$ after being scaled by the aggregate productivity shock $Z_{t}$, which follows a random walk with drift:

$$
\ln \left(Z_{t}\right)=\ln (z)+\ln \left(Z_{t-1}\right)+\varepsilon_{z t}
$$

for all $t=0,1,2, \ldots$, with $z>1$, where the serially uncorrelated innovation $\varepsilon_{z t}$ is normally 
distributed with mean zero and standard deviation $\sigma_{z}$. The shock $u_{t}$ to money demand follows the stationary autoregressive process

$$
\ln \left(u_{t}\right)=\rho_{u} \ln \left(u_{t-1}\right)+\varepsilon_{u t}
$$

for all $t=0,1,2, \ldots$, with $0 \leq \rho_{u}<1$, where the serially uncorrelated innovation $\varepsilon_{u t}$ is normally distributed with mean zero and standard deviation $\sigma_{u}$. Finally, the parameter $\phi_{m} \geq 0$ governs the magnitude of the adjustment cost for real balances, adapted from Nelson (2002) and Andreś, Loṕez-Salido, and Nelson $(2004,2009)$ to take the quadratic functional form used here. Since these costs subtract from utility along with hours worked, they have the interpretation as a time cost, and are scaled by the average growth rate parameter $z$ from (3) so as to equal zero in the model's steady state.

Thus, the household chooses $C_{t}, h_{t}, B_{t}$, and $M_{t}$ for all $t=0,1,2, \ldots$ to maximize expected utility subject to the budget constraint (1) for all $t=0,1,2, \ldots$. The first-order conditions for this problem can be written as

$$
\begin{gathered}
\Lambda_{t}=\frac{a_{t}}{C_{t}-\gamma C_{t-1}}-\beta \gamma E_{t}\left(\frac{a_{t+1}}{C_{t+1}-\gamma C_{t}}\right) \\
a_{t}=\Lambda_{t}\left(W_{t} / P_{t}\right), \\
\Lambda_{t}=\beta r_{t} E_{t}\left(\Lambda_{t+1} / \pi_{t+1}\right), \\
a_{t} v_{1}\left(\frac{M_{t}}{P_{t} Z_{t}}, u_{t}\right)-a_{t}\left(\frac{\phi_{m}}{2}\right)\left(\frac{M_{t} / P_{t}}{z M_{t-1} / P_{t-1}}-1\right)^{2} \\
-a_{t} \phi_{m}\left(\frac{M_{t} / P_{t}}{z M_{t-1} / P_{t-1}}-1\right)\left(\frac{M_{t} / P_{t}}{z M_{t-1} / P_{t-1}}\right) \\
+\beta \phi_{m} E_{t}\left[a_{t+1}\left(\frac{M_{t+1} / P_{t+1}}{z M_{t} / P_{t}}-1\right)\left(\frac{M_{t+1} / P_{t+1}}{z M_{t} / P_{t}}\right)^{2}\left(\frac{z Z_{t}}{Z_{t+1}}\right)\right] \\
=Z_{t} \Lambda_{t}\left(1-\frac{1}{r_{t}}\right),
\end{gathered}
$$

and (1) with equality for all $t=0,1,2, \ldots$, where $\Lambda_{t}$ denotes the nonnegative Lagrange 
multiplier on the budget constraint for period $t, \pi_{t}=P_{t} / P_{t-1}$ denotes the gross inflation rate between $t$ and $t+1$, and $v_{1}$ denotes the partial derivative of the function $v$ with respect to its first argument, scaled real balances.

In the special case where $\gamma=0$ and $\phi_{m}=0$, so that there is no habit formation in consumption or adjustment costs for real balances, (5) can be substituted into (8) to obtain

$$
v_{1}\left(\frac{M_{t}}{P_{t} Z_{t}}, u_{t}\right)=\frac{Z_{t}}{C_{t}}\left(1-\frac{1}{r_{t}}\right)
$$

Adapting a specification suggested by Rognlie (2016), suppose that the utility function over real balances is such that

$$
v_{1}\left(\frac{M_{t}}{P_{t} Z_{t}}, u_{t}\right)=\frac{1}{\delta}\left[\ln \left(m^{*}\right)-\ln \left(\frac{M_{t}}{P_{t} Z_{t}}\right)+\ln \left(u_{t}\right)\right],
$$

where $\delta>0$ and $m^{*}$ is a satiation level of scaled real balances, beyond which additional money holdings begin to impose marginal costs on, instead of yielding marginal benefits to, the household. Then

$$
\ln \left(\frac{M_{t}}{P_{t} Z_{t}}\right)=\ln \left(m^{*}\right)-\delta\left(\frac{Z_{t}}{C_{t}}\right)\left(1-\frac{1}{r_{t}}\right)+\ln \left(u_{t}\right),
$$

confirming that, along a steady-state growth path, real balances and consumption grow at the same rate $z$. Meanwhile, looking across steady-state growth paths, $\delta>0$ governs the interest semi-elasticity of money demand. More generally, with this specification for $v$, (8) 
becomes

$$
\begin{aligned}
& \frac{a_{t}}{\delta}\left[\ln \left(m^{*}\right)-\ln \left(\frac{M_{t}}{P_{t} Z_{t}}\right)+\ln \left(u_{t}\right)\right]-a_{t}\left(\frac{\phi_{m}}{2}\right)\left(\frac{M_{t} / P_{t}}{z M_{t-1} / P_{t-1}}-1\right)^{2} \\
& -a_{t} \phi_{m}\left(\frac{M_{t} / P_{t}}{z M_{t-1} / P_{t-1}}-1\right)\left(\frac{M_{t} / P_{t}}{z M_{t-1} / P_{t-1}}\right) \\
& +\beta \phi_{m} E_{t}\left[a_{t+1}\left(\frac{M_{t+1} / P_{t+1}}{z M_{t} / P_{t}}-1\right)\left(\frac{M_{t+1} / P_{t+1}}{z M_{t} / P_{t}}\right)^{2}\left(\frac{z Z_{t}}{Z_{t+1}}\right)\right] \\
& =Z_{t} \Lambda_{t}\left(1-\frac{1}{r_{t}}\right)
\end{aligned}
$$

\subsection{The Representative Finished Goods-Producing Firm}

During each period $t=0,1,2, \ldots$, the representative finished goods-producing firm uses $Y_{t}(i)$ units of each intermediate good $i \in[0,1]$, purchased at the nominal price $P_{t}(i)$, to manufacture $Y_{t}$ units of the finished good according to the technology described by

$$
\left[\int_{0}^{1} Y_{t}(i)^{\left(\theta_{t}-1\right) / \theta_{t}} \mathrm{~d} i\right]^{\theta_{t} /\left(\theta_{t}-1\right)} \geq Y_{t}
$$

where $\theta_{t}$ translates into a random shock to the intermediate goods-producing firms' desired markup of price over marginal cost and therefore acts like a cost push shock of the kind introduced into the New Keynesian model by Clarida, Galí, and Gertler (1999). Here, this markup shock follows the stationary autoregressive process

$$
\ln \left(\theta_{t}\right)=\left(1-\rho_{\theta}\right) \ln (\theta)+\rho_{\theta} \ln \left(\theta_{t-1}\right)+\varepsilon_{\theta t}
$$

for all $t=0,1,2, \ldots$, with $0 \leq \rho_{\theta}<1$ and $\theta>1$, where the serially uncorrelated innovation $\varepsilon_{\theta t}$ is normally distributed with mean zero and standard deviation $\sigma_{\theta}$.

Thus, during each period $t$, the finished goods-producing firm chooses $Y_{t}(i)$ for all $i \in[0,1]$ to maximize its profits, which are given by

$$
P_{t}\left[\int_{0}^{1} Y_{t}(i)^{\left(\theta_{t}-1\right) / \theta_{t}} \mathrm{~d} i\right]^{\theta_{t} /\left(\theta_{t}-1\right)}-\int_{0}^{1} P_{t}(i) Y_{t}(i) \mathrm{d} i .
$$


The first-order conditions for this problem are

$$
Y_{t}(i)=\left[P_{t}(i) / P_{t}\right]^{-\theta_{t}} Y_{t}
$$

for all $i \in[0,1]$ and $t=0,1,2, \ldots$

Competition drives the finished goods-producing firm's profits to zero in equilibrium, determining $P_{t}$ as

$$
P_{t}=\left[\int_{0}^{1} P_{t}(i)^{1-\theta_{t}} \mathrm{~d} i\right]^{1 /\left(1-\theta_{t}\right)}
$$

for all $t=0,1,2, \ldots$

\subsection{The Representative Intermediate Goods-Producing Firm}

During each period $t=0,1,2, \ldots$, the representative intermediate goods-producing firm hires $h_{t}(i)$ units of labor from the representative household to manufacture $Y_{t}(i)$ units of intermediate good $i$ according to the technology described by

$$
Z_{t} h_{t}(i) \geq Y_{t}(i)
$$

where $Z_{t}$ is the aggregate productivity shock introduced in (3).

Since the intermediate goods substitute imperfectly for one another in producing the finished good, the representative intermediate goods-producing firm sells its output in a monopolistically competitive market, setting its nominal price $P_{t}(i)$ subject to the requirement that it satisfy the representative finished goods-producing firm's demand at that price. Following Rotemberg (1982), the intermediate goods-producing firm faces a quadratic cost of adjusting its nominal price between periods, measured in terms of the finished good and given by

$$
\frac{\phi_{p}}{2}\left[\frac{P_{t}(i)}{\pi_{t-1}^{\alpha} \pi^{1-\alpha} P_{t-1}(i)}-1\right]^{2} Y_{t},
$$

where $\phi_{p} \geq 0$ governs the magnitude of the price adjustment cost, $\alpha$ is a parameter that 
lies between zero and one, with $0 \leq \alpha \leq 1$, and $\pi$ denotes the steady-state rate of inflation. According to this specification, the extent to which price setting is backward-looking depends on the magnitude of the parameter $\alpha$. When, in particular, $\alpha=1$, prices are indexed fully to past inflation, giving price setting an important backward-looking component. At the other extreme however, when $\alpha=0$, there is no indexation of prices to past inflation rates and price setting is purely forward-looking.

The cost of price adjustment makes the intermediate goods-producing firm's problem dynamic: it chooses $P_{t}(i)$ for all $t=0,1,2, \ldots$ to maximize its total real market value, proportional to

$$
E_{0} \sum_{t=0}^{\infty} \beta^{t} \Lambda_{t}\left[D_{t}(i) / P_{t}\right]
$$

where $\beta^{t} \Lambda_{t}$ measures the marginal utility value to the representative household of an additional unit of real profits received in the form of dividends during period $t$ and where

$$
\frac{D_{t}(i)}{P_{t}}=\left[\frac{P_{t}(i)}{P_{t}}\right]^{1-\theta_{t}} Y_{t}-\left[\frac{P_{t}(i)}{P_{t}}\right]^{-\theta_{t}}\left(\frac{W_{t}}{P_{t}}\right)\left(\frac{Y_{t}}{Z_{t}}\right)-\frac{\phi}{2}\left[\frac{P_{t}(i)}{\pi_{t-1}^{\alpha} \pi^{1-\alpha} P_{t-1}(i)}-1\right]^{2} Y_{t}
$$

measures the firm's real profits during the same period $t$. The first-order conditions for this problem are

$$
\begin{aligned}
0= & \left(1-\theta_{t}\right)\left[\frac{P_{t}(i)}{P_{t}}\right]^{-\theta_{t}}+\theta_{t}\left[\frac{P_{t}(i)}{P_{t}}\right]^{-\theta_{t}-1}\left(\frac{W_{t}}{P_{t}}\right)\left(\frac{1}{Z_{t}}\right) \\
& -\phi_{p}\left[\frac{P_{t}(i)}{\pi_{t-1}^{\alpha} \pi^{1-\alpha} P_{t-1}(i)}-1\right]\left[\frac{P_{t}}{\pi_{t-1}^{\alpha} \pi^{1-\alpha} P_{t-1}(i)}\right] \\
& +\beta \phi_{p} E_{t}\left\{\left(\frac{\Lambda_{t+1}}{\Lambda_{t}}\right)\left[\frac{P_{t+1}(i)}{\pi_{t}^{\alpha} \pi^{1-\alpha} P_{t}(i)}-1\right]\left[\frac{P_{t+1}(i)}{\pi_{t}^{\alpha} \pi^{1-\alpha} P_{t}(i)}\right]\left[\frac{P_{t}}{P_{t}(i)}\right]\left(\frac{Y_{t+1}}{Y_{t}}\right)\right\}
\end{aligned}
$$

and (11) with equality for all $t=0,1,2, \ldots$ 


\subsection{The Efficient Level of Output and the Output Gap}

A social planner for this economy who can overcome the frictions associated with monetary trade, sluggish price adjustment, and the monopolistically competitive structure of the intermediate goods-producing sector chooses $Q_{t}$ and $n_{t}(i)$ for all $i \in[0,1]$ to maximize the social welfare function

$$
E_{0} \sum_{t=0}^{\infty} \beta^{t} a_{t}\left[\ln \left(Q_{t}-\gamma Q_{t-1}\right)-\int_{0}^{1} n_{t}(i) \mathrm{d} i\right]
$$

subject to the aggregate feasibility constraint

$$
Z_{t}\left[\int_{0}^{1} n_{t}(i)^{\left(\theta_{t}-1\right) / \theta_{t}} \mathrm{~d} i\right]^{\theta_{t} /\left(\theta_{t}-1\right)} \geq Q_{t}
$$

for all $t=0,1,2, \ldots$. The first-order conditions for this problem are

$$
\begin{gathered}
\Xi_{t}=\frac{a_{t}}{Q_{t}-\gamma Q_{t-1}}-\beta \gamma E_{t}\left(\frac{a_{t+1}}{Q_{t+1}-\gamma Q_{t}}\right), \\
a_{t}=\Xi_{t} Z_{t}\left(Q_{t} / Z_{t}\right)^{1 / \theta_{t}} n_{t}(i)^{-1 / \theta_{t}}
\end{gathered}
$$

for all $i \in[0,1]$, and the aggregate feasibility constraint with equality for all $t=0,1,2, \ldots$, where $\Xi_{t}$ denotes the nonnegative Lagrange multiplier on the aggregate feasibility constraint for period $t$.

The second optimality condition listed above implies that $n_{t}(i)=n_{t}$ for all $i \in[0,1]$ and $t=0,1,2, \ldots$, where

$$
n_{t}=\left(\Xi_{t} / a_{t}\right)^{\theta_{t}} Z_{t}^{\theta_{t}}\left(Q_{t} / Z_{t}\right) .
$$

Substituting this last relationship into the aggregate feasibility constraint yields

$$
\Xi_{t}=a_{t} / Z_{t}
$$


Hence, the efficient level of output $Q_{t}$ must satisfy

$$
\frac{1}{Z_{t}}=\frac{1}{Q_{t}-\gamma Q_{t-1}}-\beta \gamma E_{t}\left[\left(\frac{a_{t+1}}{a_{t}}\right)\left(\frac{1}{Q_{t+1}-\gamma Q_{t}}\right)\right]
$$

for all $t=0,1,2, \ldots$. This definition of the efficient level of output implies a corresponding definition of the output gap as

$$
x_{t}=Y_{t} / Q_{t}
$$

\subsection{The Central Bank}

The central bank in the estimated model conducts monetary policy according to a variant of the Taylor (1993) rule

$$
\ln \left(r_{t} / r\right)=\rho_{r} \ln \left(r_{t-1} / r\right)+\rho_{\pi} \ln \left(\pi_{t-1} / \pi\right)+\rho_{x} \ln \left(x_{t-1} / x\right)+\varepsilon_{r t}
$$

for all $t=0,1,2, \ldots$, where $r, \pi$ and $x$ denote the steady-state values of the interest rate, inflation rate, and output gap and where response coefficients satisfying $0 \leq \rho_{r}<1, \rho_{\pi} \geq 0$, and $\rho_{x} \geq 0$ are chosen by the central bank. This policy rule allows the central bank to adjust the short-term nominal interest rate in response to movements in inflation and the modelconsistent measure of the output gap. It also allows for interest rate smoothing through the term involving the lagged interest rate. The serially uncorrelated monetary policy shock $\varepsilon_{t}$ is normally distributed with mean zero and standard deviation $\sigma_{r}$.

Although the central bank itself makes no direct reference to the growth rate of money under an interest rate rule of this form, the money demand relationship (9) serves to determine the equilibrium level of real balances $M_{t} / P_{t}$. The growth rate of nominal money $\mu_{t}=M_{t} / M_{t-1}$ is then determined by

$$
\mu_{t}=\left(\frac{M_{t} / P_{t}}{M_{t-1} / P_{t-1}}\right) \pi_{t}
$$


for all $t=0,1,2, \ldots$. To help keep track of the model's observable variables, it is useful to let

$$
g_{t}=Y_{t} / Y_{t-1}
$$

denote the growth rate of output for all $t=0,1,2, \ldots$

\subsection{Symmetric Equilibrium}

In a symmetric equilibrium, all intermediate goods-producing firms make identical decisions, so that $Y_{t}(i)=Y_{t}, h_{t}(i)=h_{t}, D_{t}(i)=D_{t}$, and $P_{t}(i)=P_{t}$ for all $i \in[0,1]$ and $t=0,1,2, \ldots$ In addition, the market clearing conditions $M_{t}=M_{t-1}+T_{t}$ and $B_{t}=B_{t-1}=0$ for money and bonds must hold for all $t=0,1,2, \ldots$. After imposing these equilibrium conditions and using (6), (11), and (12) to solve out for $W_{t} / P_{t}, h_{t}$, and $D_{t}$, section 1 of the appendix uses (1)-(5), (7), (9), (10), and (13)-(18) to form a system of 14 equations in the 14 variables $Y_{t}, C_{t}, \pi_{t}, r_{t}, M_{t} / P_{t}, Q_{t}, x_{t}, \mu_{t}, g_{t}, \Lambda_{t}, a_{t}, Z_{t}, u_{t}$, and $\theta_{t}$. Some of the real variables in this system inherit unit roots from the random walk (3) in the technology shock. However, the variables $y_{t}=Y_{t} / Z_{t}, c_{t}=C_{t} / Z_{t}, m_{t}=\left(M_{t} / P_{t}\right) / Z_{t}, q_{t}=Q_{t} / Z_{t}, \lambda_{t}=Z_{t} \Lambda_{t}$, and $z_{t}=Z_{t} / Z_{t-1}$

remain stationary and, in the absence of shocks, the economy converges to a steady-state growth path, along which all of the stationary variables are constant, with $y_{t}=y, c_{t}=c$, $\pi_{t}=\pi, r_{t}=r, m_{t}=m, q_{t}=q, x_{t}=x, \mu_{t}=\mu, g_{t}=g, \lambda_{t}=\lambda, a_{t}=1, z_{t}=z, u_{t}=1$, and $\theta_{t}=\theta$ for all $t=0,1,2, \ldots$

Equations (6) and (13), in particular, can be combined with (9) to obtain the steady-state relationship

$$
\ln (m)=\ln \left(m^{*}\right)-\delta_{r}(r-1),
$$

where

$$
\delta_{r}=\left(\frac{\delta}{r}\right)\left(\frac{\theta}{\theta-1}\right) .
$$

Since $r-1$ is the steady-state value of the net nominal interest rate, this new parameter $\delta_{r}$ measures the long-run interest semi-elasticity of money demand. 
Section 1 of the appendix also shows that the system consisting of (1)-(5), (7), (9), (10), and (13)-(18) can be log-linearized around the steady-state to describe how the economy responds to shocks. Let $\hat{y}_{t}=\ln \left(y_{t} / y\right), \hat{c}_{t}=\ln \left(c_{t} / c\right), \hat{\pi}_{t}=\ln \left(\pi_{t} / \pi\right), \hat{r}_{t}=\ln \left(r_{t} / r\right), \hat{m}_{t}=$ $\ln \left(m_{t} / m\right), \hat{q}_{t}=\ln \left(q_{t} / q\right), \hat{x}_{t}=\ln \left(x_{t} / x\right), \hat{\mu}_{t}=\ln \left(\mu_{t} / \mu\right), \hat{g}_{t}=\ln \left(g_{t} / g\right), \hat{\lambda}_{t}=\ln \left(\lambda_{t} / \lambda\right), \hat{a}_{t}=$ $\ln \left(a_{t}\right), \hat{z}_{t}=\ln \left(z_{t} / z\right), \hat{u}_{t}=\ln \left(u_{t}\right)$, and $\hat{\theta}_{t}=\ln \left(\theta_{t} / \theta\right)$ denote the percentage deviation of each variable from its steady-state level. A first-order Taylor approximation to (1) implies that $\hat{c}_{t}=\hat{y}_{t}$. First-order approximations to the remaining 13 equations then imply

$$
\begin{gathered}
(z-\beta \gamma)(z-\gamma) \hat{\lambda}_{t}=\gamma z \hat{y}_{t-1}-\left(z^{2}+\beta \gamma^{2}\right) \hat{y}_{t}+\beta \gamma z E_{t} \hat{y}_{t+1}+\left(z-\beta \gamma \rho_{a}\right)(z-\gamma) \hat{a}_{t}-\gamma z \hat{z}_{t}, \\
\hat{\lambda}_{t}=\hat{r}_{t}+E_{t} \hat{\lambda}_{t+1}-E_{t} \hat{\pi}_{t+1} \\
0=\gamma z \hat{q}_{t-1}-\left(z^{2}+\beta \gamma^{2}\right) \hat{q}_{t}+\beta \gamma z E_{t} \hat{q}_{t+1}+\beta \gamma(z-\gamma)\left(1-\rho_{a}\right) \hat{a}_{t}-\gamma z \hat{z}_{t}, \\
\hat{x}_{t}=\hat{y}_{t}-\hat{q}_{t}, \\
(1+\beta \alpha) \hat{\pi}_{t}=\alpha \hat{\pi}_{t-1}+\beta E_{t} \hat{\pi}_{t+1}-\psi \hat{\lambda}_{t}+\psi \hat{a}_{t}+\hat{e}_{t}, \\
\hat{r}_{t}=\rho_{r} \hat{r}_{t-1}+\rho_{\pi} \hat{\pi}_{t-1}+\rho_{x} \hat{x}_{t-1}+\varepsilon_{r t}, \\
\hat{u}_{t}+\hat{z}_{t}=\phi \hat{m}_{t-1}-[1+(1+\beta) \phi] \hat{m}_{t}+\beta \phi \hat{m}_{t+1}-\delta_{r} \hat{r}_{t}, \\
\hat{\mu}_{t}=\hat{z}_{t}+\hat{m}_{t}-\hat{m}_{t-1}+\hat{\pi}_{t}, \\
\hat{g}_{t}=\hat{y}_{t}-\hat{y}_{t-1}+\hat{z}_{t}, \\
\hat{a}_{t}=\rho_{a} \hat{a}_{t-1}+\varepsilon_{a t}, \\
\hat{u}_{t}=\rho_{u} \hat{u}_{t-1}+\varepsilon_{u t}, \\
\hat{z}_{t}=\varepsilon_{z t},
\end{gathered}
$$

and

$$
\hat{e}_{t}=\rho_{e} \hat{e}_{t-1}+\varepsilon_{e t}
$$


for all $t=0,1,2, \ldots$

Equations (19)-(22), which are log-linearized versions of (5), (7), (14), and (15), define the model's New Keynesian IS relationship linking movements in the output gap $\hat{x}_{t}$ to the real interest rate $\hat{r}_{t}-E_{t} \hat{\pi}_{t+1}$, with backward-looking elements introduced through habit formation in the representative household's utility function. In the special case where $\gamma=0$, so that habit formation is absent, these equations combine to yield the simpler, purely-forward looking specification

$$
\hat{x}_{t}=E_{t} \hat{x}_{t+1}-\left(\hat{r}_{t}-E_{t} \hat{\pi}_{t+1}\right)+\left(1-\rho_{a}\right) \hat{a}_{t} .
$$

Meanwhile (23), the linearized form of (13), is the New Keynesian Phillips curve, again with a backward-looking component entering when $\alpha>0$, so that sticky individual goods prices are indexed to past inflation. In (23), the cost push shock has been renormalized as $\hat{e}_{t}=-\left(1 / \phi_{p}\right) \hat{\theta}_{t}$ and the new parameters $\rho_{e}=\rho_{\theta}$ and $\psi=(\theta-1) / \phi_{p}$ have been defined so that $\varepsilon_{e t}$ is normally distributed with mean zero and standard deviation $\sigma_{e}=\sigma_{\theta} / \phi_{p}$. Together with the Taylor rule (24) for monetary policy, derived directly from (16), this first block of equations works, exactly as in textbook New Keynesian models, to determine the dynamic behavior of inflation, output and the output gap, and the short-term nominal interest rate without reference to the behavior of the money stock, whether real or nominal.

The addition of the money demand relationship (25) implied by (9), however, serves to determine the level of real balances in equilibrium under the Taylor rule (24). In (25), the adjustment cost parameter for real balances is renormalized as $\phi=\delta \phi_{m}$. Focusing again on the special case where $\gamma=0$ and $\phi_{m}=0$, so that there is no habit formation in consumption or adjustment costs for real balances, (19) and (25) imply that

$$
\hat{m}_{t}=\delta_{r}(r-1) \hat{y}_{t}-\delta_{r} \hat{r}_{t}+\hat{u}_{t}
$$

The coefficient on $\hat{y}_{t}$ in this last relationship will be small for modest levels of the steady-state nominal interest rate; hence, in this economy, real money demand depends on the permanent 
component of income, captured by $Z_{t}$, more than the transitory component $\hat{y}_{t}$. Once again, $\delta_{r}$ is the interest semi-elasticity of money demand and $u_{t}$ acts like a money demand shock. Finally, in this linearized system, (26) and (27) follow from (17) and (18) to determine the growth rate of the nominal money stock and aggregate output, and (28)-(31), which restate (2)-(4) and (10), govern the dynamics of the preference, productivity, money demand, and cost push shocks.

During the period from 2009 through 2015, when the Federal Reserve held the federal funds rate in a range close to zero, the Taylor rule (24) is replaced in the estimated model by the zero interest rate condition

$$
\hat{r}_{t}=-\ln (r) .
$$

Similarly, to generate counterfactual outcomes under which monetary policy is described by a rule for the money growth rate, (24) is replaced by

$$
\hat{\mu}_{t}=\rho_{m m} \hat{\mu}_{t-1}+\rho_{m \pi} \hat{\pi}_{t-1}+\rho_{m x} \hat{x}_{t-1} .
$$

When $\rho_{m m}=\rho_{m \pi}=\rho_{m x}=0,(33)$ reduces to the same constant money growth rule studied earlier by Ireland (2000), Collard and Dellas (2005), and Galí (2015) and advocated most famously of course, by Friedman (1968). When, by contrast, $\rho_{m x}<0$ and $\rho_{m \pi}<0$, this more general money growth rate rule allows monetary policy to stabilize the output gap and inflation actively in response to other shocks that hit the economy. When, in addition, $\rho_{m m}>0$, the rule prescribes a gradual response of money growth to movements in inflation and the output gap, in much the same way that the Taylor rule (24) with interest rate smoothing does. 


\section{Data, Priors, and Estimation Methods}

Kulish, Morley, and Robinson (2017) develop the methods used to solve and estimate the New Keynesian model described above while accounting for the period of zero nominal interest rates from 2009 through 2015. These methods, summarized as they are applied here in sections 2-5 of the appendix, solve the model using an algorithm similar to Guerrieri and Iacoviello's (2015), but treat agents' expectations of the duration of the zero interest rate episode as a time-varying parameter that can be estimated jointly with the structural parameters that enter directly into (19)-(31).

All data used to estimate the model are quarterly and run from 1983:1 through 2018:3. For the periods from 1983:1 through 2008:4 and from 2016:1 through 2018:3 during which the Federal Reserve was targeting the federal funds rate at levels bounded away from zero, the estimation procedure treats four of the model's variables as observable. Output growth is measured by quarterly changes in the natural log of real GDP, converted to per capita terms using the civilian noninstitutional population, age 16 and over. ${ }^{3}$ Inflation is measured by quarterly changes in the log of the GDP deflator, and the short-term nominal interest rate is measured by the effective federal funds rate, divided by 400 to convert the annualized figures in the data to quarterly rates as they appear in the model. Finally, nominal money growth is measured by quarterly changes in the Divisia M2 index of monetary services, again converted to per capita terms. Serletis and Gogas (2014) and Belongia and Ireland (2019a) find evidence of stable long-run money demand relationships for Divisia M2, motiviating the choice of that monetary aggregate here. ${ }^{4}$

For the period from 2009:1 through 2015:4 during which the Federal Reserve held shortterm interest rates close to zero, (32) replaces (24) in the estimated model, and the federal

\footnotetext{
${ }^{3}$ In light of the erratic behavior, noted by Edge and Gurkaynak (2010, p.218) and caused by periodic rebasings of the Census Bureau series for the US population, the trend values for this series, extracted using the Hodrick-Prescott filter with smoothing parameter 1600, are used in place of the raw data in constructing per-capita measures here.

${ }^{4}$ All data series are drawn from the Federal Reserve Bank of St. Louis' FRED database, except that for Divisia M2, which is available through the Center for Financial Stability's website. For details on the construction of the CFS Divisia monetary series, see Barnett, Liu, Mattson, and van den Noort (2013).
} 
funds rate is dropped from the list of observable variables. For this interval, the model's solution depends not only on the structural parameters that enter into the New Keynesian model, but also on the duration, denoted by $\tau_{t}$, of the zero interest rate episode expected by private agents in the model during each period $t$. Here, as in Kulish, Morley, and Robinson (2017), these expected durations are treated as parameters that can be estimated based on the forward-looking New Keynesian model's implications for the effects that expected future interest rates have on the remaining observables: output growth, inflation, and the nominal money growth rate.

Prior to estimation, values for $z, \pi$ and $\beta$ are fixed at values that match the model's steady-state output growth, inflation, and short-term nominal interest rates to the average values of those same variables in the pre-crisis subsample of data running from 1983:1 through 2008:4. Likewise, the steady-state money growth rate $\mu$ is treated as another free parameter, fixed to match the average growth rate of Divisia M2 over the same 1983:1-2008:4 period. Thus, in the estimation, all four observable series are re-expressed as deviations from their pre-crisis mean values. This approach is intended, in particular, to force the estimated model to attribute the Great Recession of 2007-09 and the subsequent sluggish recovery to one or more large and highly persistent shocks instead of to downward shifts in the steady-state rates of output growth and inflation. Bayesian priors must then be specified and calibrated for two vectors of parameters: the remaining structural parameters from the New Keynesian model (19)-(31) and the time-varying expected durations of the zero nominal interest rate episode over the 28 quarters from 2009:1 through 2015:4.

Priors for the 16 structural parameters are summarized in table 1 and described in more detail by the red lines in figure 1. As the table shows, these parameters are divided into three groups. The habit formation and price indexation parameters $\gamma$ and $\alpha$, the interest rate smoothing parameter $\rho_{r}$, and the autoregressive parameters $\rho_{a}, \rho_{u}$, and $\rho_{e}$ all lie between zero and one. Independent beta prior distributions are therefore assigned to these parameters, each with its two shape coefficients calibrated to match the prior mean and standard 
deviation listed in table 1. In particular, prior distributions for $\gamma$ and $\alpha$ are centered at 0.5 , with standard deviations large enough to allow for values closer to zero or one. The prior distributions for $\rho_{r}, \rho_{a}, \rho_{u}$, and $\rho_{e}$ reflect more confidence in the beliefs, first, that Federal Reserve policy over the sample period is characterized by substantial interest rate smoothing and, second, that while the preference and money demand shocks hitting the economy are highly persistent, the cost push shocks are less so.

The Phillips curve slope parameter $\psi$, the interest semi-elasticity of money demand $\delta_{r}$, the adjustment cost parameter for real balances $\phi$, and the monetary policy response coefficients $\rho_{\pi}$ and $\rho_{x}$ are all nonnegative. Independent gamma prior distributions are assigned to these parameters, with shape and scale coefficients chosen to match the means and standard deviations listed, again, in table 1 . The prior mean for $\psi$ is set equal to 0.1 , the calibrated value used by Ireland $(2000,2004 a, 2004 b, 2007,2011)$. Prior means of 5 for $\delta_{r}$ and 10 for $\phi$ are chosen somewhat arbitrarily, but large standard deviations reflect the considerable uncertainty regarding the magnitudes of these parameters before estimation. Prior means of 0.4 for $\rho_{\pi}$ and 0.2 for $\rho_{x}$ imply a policy response to changes in inflation twice the size of the response to changes in the output gap. Coupled with the prior mean of 0.75 for the interest rate smoothing parameter $\rho_{r}$, these settings translate into long-run responses $\rho_{\pi} /\left(1-\rho_{r}\right)$ and $\rho_{x} /\left(1-\rho_{r}\right)$ of the interest rate to changes in inflation and the output gap equal to 1.6 and 0.8 .

Finally, the parameters $\sigma_{a}, \sigma_{z}, \sigma_{u}, \sigma_{e}$, and $\sigma_{r}$ measuring the standard deviations of the New Keynesian model's five structural shocks are assigned prior distributions implied by the assumption that each of the associated variances has an inverse chi-squared distribution with four degrees of freedom. ${ }^{5}$ The scale coefficient for the inverse chi-squared distribution is set to $0.01^{2}$ for the preference, productivity, and money demand shocks and $0.0025^{2}$ for the cost push and monetary policy shocks. These settings give $\sigma_{a}, \sigma_{z}$, and $\sigma_{u}$ priors means equal to 0.0125 and $\sigma_{e}$ and $\sigma_{r}$ prior means of 0.0031. The implied standard deviations, meanwhile,

\footnotetext{
${ }^{5}$ Adjemian (2016) refers to this induced distribution as the "inverted gamma distribution of type I."
} 
leave considerable leeway for the data to push the posterior distributions towards larger or smaller values of each of these volatility parameters.

Priors for the time-varying expected duration of the zero nominal interest rate episode are formed, as described by Kulish, Morley, and Robinson (2017, p.40), with the help of data from the Blue Chip Financial Forecasts from 2009:1 through 2010:4 and the Federal Reserve Bank of New York Primary Dealers Survey from 2011:1 through 2015:4. The Blue Chip survey records the expected date of funds rate liftoff from zero reported by approximately 40 forecasting firms; the cross-sectional distribution of these forecasts is interpreted as reflecting the probabilities of various durations of the zero interest rate episode. The Primary Dealers Survey, meanwhile, asks each individual respondent to assign probabilities to different liftoff dates; the average probabilities, as reported by the New York Fed, are used, similarly, as measures of the probabilities of different durations. Kulish, Morley, and Robinson (2017) form their prior as an equally-weighted average of the probabilities implied by these surveys and a uniform distribution over all durations ranging from 1 to 23 quarters. ${ }^{6}$ Their estimation exercise, however, uses data on the term structure of interest rates as well as macroeconomic variables to glean additional information about expected durations of the zero interest rate episode using Smets and Wouters' (2007) medium-scale New Keynesian model, augmented with a model of the yield curve based on the expectations hypothesis. Here, where only macroeconomic data are used for estimation, a larger weight of 80 percent is assigned to the survey evidence, with the remaining 20 percent attached to a uniform distribution over durations from 1 to 23 quarters. The resulting independent prior distributions for all of the 28 expected durations prevailing from 2009:1 through 2015:4 are plotted as red lines in figures 2 and 3 .

\footnotetext{
${ }^{6}$ The upper bound of 23 quarters imposed by the prior on the expected duration of the zero interest rate episode reflects the observation that, in the survey data, zero probabilities are assigned to all durations longer than 23 quarters.
} 


\section{Results}

\subsection{Bayesian Estimates}

Table 2 summarizes the posterior distributions of the New Keynesian model's 16 structural parameters, while figure 1 displays more fully the posterior densities using blue bars, comparing them to the priors, described above and outlined in red. These posterior distributions assign more weight to higher values for the habit formation parameter $\gamma$ and lower values for the price indexation parameter $\alpha$, compared to the priors. The posterior density for $\psi$ implies a much flatter Phillips curve than does the prior, perhaps reflecting the muted response of inflation to more dramatic movements in real variables during and since the Great Recession. ${ }^{7}$ At first glance, the estimated money demand semi-elasticity appears quite large. However, with interest rates measured here in quarterly terms, $\delta_{r}$ has to be divided by 4 to obtain the semi-elasticity with respect to the interest rate quoted, more conventionally, in annual terms. Thus, in fact, the posterior median of $\delta_{r}=13.4$ is quite similar to the semi-elasticity estimates, ranging from 3.17 to 3.66, obtained by Belongia and Ireland (2019a) from cointegrating money demand relationships for Divisia M2. Estimates of $\phi$ centered near 12 point to the importance of adjustment costs for real balances, confirming conclusions from Nelson (2002) and Andrés, López-Salido, and Nelson (2004, 2009).

Posterior estimates of the parameters $\rho_{r}, \rho_{\pi}$ and $\rho_{x}$ from the Taylor rule (24) imply an even larger degree of interest rate smoothing and a more balanced response of policy to changes in the output gap and inflation than suggested by the prior. Estimates of $\rho_{a}$ and $\sigma_{a}$ suggest that non-monetary aggregate demand disturbances have been large and persistent over the sample period. Estimates of $\rho_{u}$ and $\sigma_{u}$, meanwhile, show that even

\footnotetext{
${ }^{7}$ The formula displayed by Del Negro, Giannoni, and Schorfheide (2015, p.174) can be used together with information displayed in table A-2 of the appendix to that same paper to compute the Phillips curve slope coefficient (labeled $\kappa$ ) implied by the posterior mode from estimating both Smets and Wouters' (2007) medium-scale New Keynesian DSGE model and an extended version featuring additional financial frictions developed specifically to explain the behavior of inflation over the post-crisis period. The posterior mode at $\psi=0.0169$ found here is comparable to the modal value of $\kappa=0.0120$ from the Smets-Wouters model but substantially larger than the modal value of $\kappa=0.0018$ from the extended model with financial frictions.
} 
more highly persistent money demand shocks have been important, too. Earlier results from Ireland (2000), Collard and Dellas (2005), and Galí (2015) strongly suggest that these money demand shocks will become an important source of additional macroeconomic volatility when the estimated Taylor rule is replaced by one calling for a constant rate of money growth. Less certain, however, is whether a money growth rule of the more general form (33) can cope more successfully with these disturbances. Finally, in figure 2, the posterior density for $\sigma_{z}$, measuring the volatility of productivity shocks, tightens but remains centered near its prior mean, while the volatility parameters $\sigma_{e}$ and $\sigma_{r}$ for the cost push and monetary policy shocks appear smaller, relative to values initially suggested by the prior.

Figures 2 and 3 show that the posterior distributions for the expected durations of the zero nominal interest rate episode overlap heavily with the corresponding priors, reflecting the absence of the additional term structure data that Kulish, Morley, and Robinson (2017) use to sharpen their estimates of these parameters. While the macroeconomic data do contribute modestly to determining the shape of these posterior distributions, to a large extent the expected durations here are essentially calibrated based on the survey data used to formulate the priors. Even by themselves, however, these survey data are useful in incorporating into the estimated model the shift in expectations towards much longer durations of the zero nominal interest rate episode that Swanson and Williams (2014) observe in late 2010, as well as the gradual reduction in expected durations as the economy continued to recover in 2014 and 2015.

Figure 4 plots the median paths from the posterior distributions of the New Keynesian model's five structural disturbances. ${ }^{8}$ Not surprisingly, the estimated model attributes the Great Recession, with its accompanying declines in inflation and interest rates, to a series of large, adverse preference shocks. Unfavorable productivity shocks also appear throughout the post-2008 period, contributing to weakness in real GDP growth but also explaining why

\footnotetext{
${ }^{8}$ These paths are constructed from draws from the posterior distribution for each shock, taken using Durbin and Koopman's (2002) simulation-smoother for the unobservable states, as described in part 6 of the appendix.
} 
inflation did not fall even further.

Since the previous results presented by Ireland (2000), Collard and Dellas (2005), and Galí (2015) suggest that money demand shocks pose the biggest challenge to the success of monetary policies that focus on targeting money growth instead of interest rates, the middle row of figure 4 plots the median paths for both the money demand shock $\hat{u}_{t}$ in levels and the serially uncorrelated innovation $\varepsilon_{u t}$ to this highly persistent shock. The sharp decline in $\hat{u}_{t}$ during the early 1990s that is estimated here coincides with the period of "missing M2" analyzed by Duca (2000), which as noted by Orphanides and Porter (2000) worked to throw off track the predictions of Hallman, Porter, and Small's (1991) "P-star" model, given its assumption that M2 velocity would converge more quickly back to a constant long-run mean. ${ }^{9}$ The estimated path for $\hat{u}_{t}$ remains stable over a period extending from the mid-1990s through 2008, before moving sharply higher during and after the Great Recession of 200709. Anderson, Bordo, and Duca (2017) detect a similar increase in post 2008 M2 demand, relative to what would be expected based on movements in income and interest rates, which they attribute to flight-to-quality portfolio dynamics triggered by the financial crisis. With specific focus on repairing the P-star model, however, Belongia and Ireland (2015, 2017) show that these shifting but highly persistent trends in money demand need not present an obstacle to effective policymaking via money growth targeting. Precisely because the trends are so persistent, they can be recognized by policymakers in real time, and successfully accommodated by gradual shifts in the target for money growth so as to stabilize output growth, inflation, and nominal GDP growth as their product.

More problematic are the innovations $\varepsilon_{u t}$ to the money demand shock, which are unpredictable from past data and therefore more likely to contribute to volatility in output and inflation, not only under constant money growth, but also under more general rules of the

\footnotetext{
${ }^{9}$ The first footnote in Hallman, Porter, and Small (1991) credits Federal Reserve Chair Alan Greenspan for suggesting the idea behind the P-star model. Thus, that model is of historical interest as one of the last quantity-theoretic models consulted regularly by high-level officials at the Federal Reserve Board. Similarly, the paper itself remains noteworthy as one of the last quantity-theoretic studies to be published in a leading, general-interest economics journal.
} 
form in (33). Consistent with the estimates of $\sigma_{u}$ reported earlier, figure 4 confirms that these innovations have been large, frequently exceeding 2 percent in both directions, positive and negative. But while, for the sake of consistency, all of the model's estimated innovations are interpreted as unpredictable in the counterfactual scenarios discussed below, it should be noted that at least some of the apparent high-frequency volatility in money demand that shows up in the estimated time path for $\varepsilon_{u t}$ in figure 4 reflects institutional changes that, to the contrary, the Fed might have anticipated in advance. Most notably, the large positive innovation $\varepsilon_{u t}$ estimated to have occurred in the third quarter of 2011, more than three standard deviations in magnitude, coincides with two regulatory changes discussed by Judson, Schlusche, and Wong (2014, pp.11-12): first, changes in FDIC insurance rates that helped banks bring offshore deposits back to the US and, second, the lifting of the longstanding prohibition against paying interest on demand deposits which triggered additional portfolio shifts back into M2. Even in real time, therefore, the rapid growth in Divisia M2, exceeding 17 percent on an annualized basis for 2011:3, would not have been a true surprise even though, in the estimated model, it appears as such.

\subsection{A Flexible Money Growth Rule}

Table 3 begins to compare the US economy's actual performance under the estimated Taylor rule to its hypothetical performance under counterfactual money growth rules. In the estimated model, output growth, inflation, the nominal interest rate, and the money growth rate are all observable. Hence, the Bayesian estimation procedure treats the historical standard deviations of those same variables as observable as well; therefore, these are constant across the first three columns of the table's first four rows. The New Keynesian model's output gap $\hat{x}_{t}$, however, remains unobservable: even its historical behavior must be estimated together with the model's other parameters. ${ }^{10}$

Although the earlier studies by Ireland (2000), Collard and Dellas (200) and Galí (2015)

\footnotetext{
${ }^{10}$ Again, paths for the output gap are constructed from draws taken using Durbin and Koopman's (2002) simulation-smoother for the model's unobservable states.
} 
all found that a constant money growth rule produced excess volatility after money demand shocks relative to an interest rate rule, none of them considered the alternative of a money growth rule that adapted flexibly to changing macroeconomic conditions in the same manner as the Taylor rule. Relative to the Taylor rule, in fact, one potential advantage to more flexible money growth rules of the form shown in (33) is that they do not require the aggressive response to inflation needed by interest rate rules to ensure the stability of a unique rational expectations equilibrium. Instead, money growth rules can stabilize long-run inflation simply by pinning down the average rate of money growth and focusing more directly on stabilizing the output gap over shorter time horizons.

Though no exhaustive attempt has been made here to identify the optimal money growth rule, search over a grid of values for the parameters reveals that setting $\rho_{m m}=1, \rho_{m \pi}=$ 0 , and $\rho_{m x}=-0.125$ delivers impressive performance in response to the array of shocks estimated to have hit the US economy over the 1983:1-2018:3 sample period, while minimizing the duration and importance of the episode, during and following the financial crisis and Great Recession, over which the short-term nominal interest rate fluctuates in a range near zero. This rule, which specializes (33) as

$$
\hat{\mu}_{t}=\hat{\mu}_{t-1}-0.125 \hat{x}_{t-1}
$$

generates modest but highly persistent adjustments in money growth. These adjustments work, directly, to stabilize the output gap and, indirectly, to stabilize inflation as well.

The middle columns of table 3 summarize the posterior distributions of output growth, inflation, the nominal interest rate, the money growth rate, and the output gap after the estimated Taylor rule (24) is replaced by the flexible money growth rule (34), holding all other parameters and disturbances fixed at their estimated values. Thus, these counterfactual simulations confront the central bank with the same patterns of preference, productivity, money demand, and cost push shocks estimated to have hit the US economy over the 1983:1- 
2018:3 sample period, but replace the Federal Reserve's historical policy of interest rate management, including the forward guidance used to lengthen the expected duration of the zero nominal interest rate episode, with the policy dictated by the flexible money growth rule instead.

As noted above, the form of the model's money demand relationship, implied by (9) and (25), allows the nominal interest rate to fall below zero in a well-defined rational expectations equilibrium. If the counterfactual path for the interest rate were to fall far below zero for an extended period of time, a concern might arise that the private financial system would adapt to profit from the spread between the zero interest rate on currency and the negative nominal interest rate on bonds. It will be confirmed below, however, that in each of the counterfactual scenarios considered here, the episode of negative nominal interest rates is moderate and, in fact, considerably shorter than the seven-year period during which the Federal Reserve kept its federal funds rate target in a range close to zero.

Table 3 reveals that the flexible money growth rule (34) holds the volatility of output growth, inflation, and the output gap at levels closely approximating those achieved under the estimated rule. Figures 5-8 add detail, by illustrating how that rule allows the output gap and inflation to respond to shocks in ways that resemble how they behave under the estimated interest rate rule. These figures compare the impulse responses under the estimated interest rate rule and the flexible money growth rule of output growth, inflation, the nominal interest rate, the money growth rate, and the output gap to one-standard-deviation preference, productivity, money demand, and cost push shocks, when the parameters of the structural model are set equal to their posterior modes shown in table $2 .^{11}$

Figure 5, in particular, reveals that both the estimated interest rate rule and the flexible money growth rule produce a monetary tightening that virtually eliminates the inflationary effects of an expansionary preference shock; the same monetary tightening helps stabilize output growth and the output gap as well. In figure 6, meanwhile, the estimated interest

\footnotetext{
${ }^{11}$ Under the estimated rule, these impulse responses are generated from the solution to (19)-(31), assuming that monetary policy remains unconstrained by the perceived zero lower interest rate bound.
} 
rate rule stabilizes inflation following a productivity shock; to do so, it produces the increase in money growth that Ireland (1996) shows is necessary to generate, under sticky prices, the efficient increase in output that keeps the output gap unchanged. Likewise, the flexible money growth rule (34) calls for a monetary expansion after a favorable productivity shock that allows output to adjust more efficiently and minimizes the response in inflation.

Figure 7 confirms that here, as in Poole's (1970) classic Keynesian analysis, the estimated interest rate rule, by holding the short-term nominal rate fixed, insulates output growth, inflation, and the output gap by fully accommodating a shock to money demand. The flexible money growth rule falls a bit short of achieving this ideal, but nevertheless generates a persistent increase in money supply growth that largely accommodates the increase in money demand. It is noteworthy that these stabilizing effects appear even though, under the flexible money growth rule, the central bank responds to the output gap with a onequarter lag. To the extent that the central bank could detect money demand shocks within the quarter and respond to them directly, the rule's performance could be improved still further. Finally, figure 8 shows impulse responses to cost push shocks under (34) that come close to replicating those that appear under the estimated interest rate rule.

\subsection{Constant Money Growth}

Consistent with the earlier results from Ireland (2000), Collard and Dellas (2005), and Galí (2015), the results in last three columns of table 3 suggest strongly that macroeconomic volatility would have been amplified greatly if the Federal Reserve had followed a policy directed at holding the growth rate of Divisia M2 perfectly fixed by setting $\rho_{m m}=\rho_{m \pi}=$ $\rho_{m x}=0$ in (33), again holding all other parameters and disturbances fixed at their estimated values. Median estimates of the standard deviations of output growth and inflation under the constant money growth rate rule are more than 50 percent larger than those under the estimated policy rule. Volatility in the output gap, meanwhile, increases by a factor of three.

Figures 5-8 again add detail. In figure 5, the monetary tightening prescribed by both 
the estimated interest rate rule and the flexible money growth rule does not occur under the constant money growth rule. Hence, under constant money growth, output growth, inflation, and the output gap all display considerably more volatility in response to preference shocks. Similarly, in figure 6, the increase in money growth that helps the economy respond more efficiently to a productivity shock under both the estimated interest rate rule and the flexible money growth rule is not generated by the constant money growth rule. Hence, conditional on the productivity shock, output growth is perversely more stable under the constant money growth rate rule, even as inflation and the output gap become more volatile. As expected, figure 7 shows that the constant money growth rule, quite unlike the flexible money growth rule, allows money demand shocks to contribute greatly to macroeconomic volatility. Finally, in figure 8, the constant money growth rule does a slightly better job than the estimated interest rate rule and the flexible money growth rule of stabilizing inflation in response to an unfavorable cost push shock, at the cost of allowing for much greater variability in output growth and the output gap. Overall, therefore, the performance of the constant money growth rule appears quite poor, relative to both the estimated interest rate rule and the more flexible money growth rule (34).

\subsection{Counterfactual Simulations}

Figure 9 completes the analysis by plotting the median paths for output growth, inflation, the nominal interest rate, the money growth rate, and the output gap from the posterior distributions implied by the estimated model and the two counterfactual money growth rules. Its right-hand panels confirm that measured by output growth or the output gap, the Great Recession would have been considerably more severe under the constant money growth rule. Inflation would not only have been more volatile, but the US economy would have experienced recurring, though brief, episodes of deflation even before the financial crisis in 2008. Under constant money growth, however, the short-term nominal interest rate would have fallen below zero for only four quarters, between 2009:2 and 2010:1, reaching a low of 
-0.80 , similar the to target maintained by the Swiss National Bank over the entire period since 2015, in 2009:3.

The flexible money growth rule (34), again by sharp contrast, delivers additional stimulus that would have closed the negative output gap by the end of 2009. The large money demand shock in 2011:3 temporarily pushes output back below its efficient level. As noted above, however, this estimated disturbance to money demand, though interpreted by the model as an exogenous and unpredictable shock, reflects legal and institutional developments known to policymakers in advance; it might have been anticipated and at least partially accommodated in actual practice. The flexible rule still produces a smoother time path for money growth than that observed historically. Most importantly, like the constant money growth rule, it requires only four quarters of negative interest rates. Along the counterfactual path, the short-term interest rate drops to -1.06 percent in 2010:1 before rebounding to -0.33 percent in $2010: 2,-0.59$ percent in $2010: 3,-0.24$ in 2010:4, and zero in 2011:2; then, through the end of the sample period, interest rates return to levels similar to those prevailing through much of the 1990s and 2000s. Additionally, under (34), inflation remains positive, before, during, and after the financial crisis.

Results from counterfactual simulations in Belongia and Ireland (2018a) suggest that the US economy would have recovered more quickly from the Great Recession even under a constant money growth rule. There are two explanations for the differences between those previous results and ones presented here. First, Belongia and Ireland (2018a) use a structural vector autoregressive time series model with more flexible dynamics that allow changes in money growth to have effects on output and inflation even after controlling for movements in the short-term nominal interest rate. Thus, in the VAR, stability in money growth contributes to stability in output and inflation as well. Here, by contrast and as noted above, the New Keynesian model puts constant money growth rules at a disadvantage, by assuming that monetary policy actions have an impact on output and inflation exclusively through their effects on the current and expected future path of interest rates. To the 
extent that changes in money growth do play a separate role in the monetary transmission mechanism, as suggested by the empirical results in Belongia and Ireland (2018a, 2018b), the case for money growth rules grows stronger. Second, the simulations in Belongia and Ireland (2018a) hold money growth constant during and after 2008, but at rates that are higher than full-sample historical average. Therefore, though they call for constant money growth over the post-2008 period, the policy rules considered previously share with the flexible money growth rule (34) considered here the implication that money growth should respond, countercyclically, to movements in the output gap.

Even better counterfactual performance appears under policy rules of the same form as (34), but with larger weights on the lagged output gap. These alternative rules, however, also cause interest rates to fall more deeply below zero, for longer periods of time, during and after the Great Recession. For a central bank worried about the effects of an extended period of negative interest rates on the financial system, another possibility would be to adopt, in times of normal economic growth and inflation, a money growth rule like (34) that responds more aggressively to changes in the output gap, but then to moderate that output gap response when interest rates approach or fall below zero, in the same way that the Federal Reserve declined to push its federal funds rate target below zero after 2008. What is particularly impressive here, however, is that the simple rule (34) delivers satisfactory macroeconomic performance throughout the entire 1983:1-2018:3 sample period, while promoting a strong recovery with a much shorter episode of exceptionally low interest rates following the financial crisis and Great Recession of 2007-09.

Finally, one perennial criticism of a monetary policy strategy based on money growth is that it would produce excessive volatility in interest rates. In figure 9 , the nominal interest rate does exhibit a modest degree of variability at high frequencies under the flexible and constant money growth rules that gets smoothed out by the estimated interest rate rule. The graphs in figure 9 suggest and the statistics in table 3 confirm, however, that the short-term interest rate actually has a lower standard deviation under the money growth rules than it 
did, historically, under the estimated interest rate rule.

\section{Conclusion}

Historically, the Federal Reserve has conducted monetary policy by managing interest rates. New Keynesian models like the one estimated here justify this approach. Within these models, simple interest rate rules of the form proposed by Taylor (1993) capture well the Fed's actual interest rate decisions, work effectively to insulate the economy from the effects of money demand disturbances, and help the economy adjust more efficiently to other, nonmonetary shocks. In these same models, constant money growth rules like those proposed by Friedman (1968) perform quite poorly. Consistent with Poole's (1970) more traditional Keynesian analysis, holding money growth constant in New Keynesian models allows money demand shocks to contribute significantly to additional macroeconomic volatility. Constant money growth rules fail, as well, to deliver the appropriate monetary response to other disturbances that require output and inflation to adjust.

The limitations of interest rate rules, however, are highlighted by more recent experi-

ence during and since the financial crisis and Great Recession of 2007-09. After lowering its federal funds rate target to a range close to zero, the Fed employed other, less conventional strategies such as forward guidance about the future interest rate path and large scale purchases of longer-term Treasury bonds and mortgage-backed securities in an attempt to deliver additional monetary stimulus and help the economy recover. These strategies led to a five-fold increase in the monetary base that now must be unwound, and also required the introduction of interest payments on reserves, a practice which must continue until the Fed's balance sheet reverts to pre-crisis levels.

This paper suggests an alternative approach that would have avoided these complications, and that works well in good times and in bad. Departing from the strict confines of Friedman's constant money growth rule, it identifies a simple but slightly more flexible 
alternative that, in the same spirit of the Taylor rule, adjusts the rate of money growth, modestly and gradually, in response to movements in the output gap. Even without a direct response to money demand shocks, this rule helps the central bank accommodate those disturbances and, more generally, allows monetary policy to pursue short-run stabilization objectives even as it maintains an environment of nominal stability through its choice of the long-run money growth rate.

Counterfactual simulations reveal that this flexible money growth rule would have produced macroeconomic stability over the 1983:1-2018:3 sample period comparable to that observed, historically, under the estimated interest rate rule. Moreover, by targeting the rate of money growth and allowing interest rates to adjust, as needed, to maintain equilibrium in the market for bonds, the simulations show that this rule would have generated a more rapid recovery in both output and inflation after 2009, without resorting to forward guidance and with exceptionally low interest rates prevailing for only one year.

Notably, these beneficial effects appear even in a standard New Keynesian model in which, by assumption, monetary policy actions are transmitted to the economy through their impact on interest rates and the stability of the money growth rate itself offers no additional advantage. To the extent that other channels of monetary transmission, like those identified empirically by Belongia and Ireland (2018a, 2018b), operate in the US economy, policy rules focusing on money growth instead of interest rates may offer further advantages not captured here. And to the extent that the money demand disturbances interpreted as exogenous and unpredictable here reflect legal and institutional changes known in advance to the Fed, they could be accommodated even under a money growth rule, improving policy still further.

The Fed's recent experiments with forward guidance, large-scale asset purchases, interest on reserves, and reverse repurchase agreements show that institutional arrangements can be changed, dramatically and on short notice, whenever circumstances demand more from monetary policy. In the wake of these experiments, shifting away from interest rate management and towards targeting money growth instead offers a simpler alternative, worthy of 
more serious consideration.

\section{References}

Adjemian, Stéphane. "Prior Distributions in Dynare." Manuscript: Université du Maine, April 2016.

Anderson, Richard G., Michael Bordo, and John V. Duca. "Money and Velocity During Financial Crises: From the Great Depression to the Great Recession." Journal of Economic Dynamics and Control 81 (August 2017): 32-49.

Andrés, Javier, J. David López-Salido, and Edward Nelson. "Tobin's Imperfect Asset Substitution in Optimizing General Equilibrium." Journal of Money, Credit, and Banking 36 (August 2004): 665-690.

Andrés, Javier, J. David López-Salido, and Edward Nelson. "Money and the Natural Rate of Interest: Structural Estimates for the United States and Euro Area." Journal of Economic Dynamics and Control 33 (March 2009): 758-776.

Barnett, William A., Jia Liu, Ryan S. Mattson, and Jeff van den Noort. "The New CFS Divisia Monetary Aggregates: Design, Construction, and Data Sources." Open Economies Review 24 (February 2013): 101-124.

Belongia, Michael T. and Peter N. Ireland. "A 'Working' Solution to the Question of Nominal GDP Targeting." Macroeconomic Dynamics 19 (April 2015): 508-534.

Belongia, Michael T. and Peter N. Ireland. "Circumventing the Zero Lower Bound with Monetary Policy Rules Based on Money." Journal of Macroeconomics 54 (December 2017, Part A): 42-58.

Belongia, Michael T. and Peter N. Ireland. "Targeting Constant Money Growth at the Zero Lower Bound." International Journal of Central Banking 14 (March 2018a): 159-204. 
Belongia, Michael T. and Peter N. Ireland. "A Classical View of the Business Cycle." Manuscript. Chestnut Hill: Boston College, October $2018 b$.

Belongia, Michael T. and Peter N. Ireland. "The Demand for Divisia Money: Theory and Evidence." Manuscript. Chestnut Hill: Boston College, January 2019a.

Belongia, Michael T. and Peter N. Ireland. "Rules versus Discretion: Inference Gleaned from Greenbook Forecasts and FOMC Decisions." Manuscript. Chestnut Hill: Boston College, February $2019 b$.

Clarida, Richard, Jordi Galí, and Mark Gertler. "The Science of Monetary Policy: A New Keynesian Perspective." Journal of Economic Literature 37 (December 1999): 1661-1707.

Collard, Fabrice and Harris Dellas. "Poole in the New Keynesian Model." European Economic Review 49 (May 2005): 887-907.

Cook, Timothy. "Determinants of the Federal Funds Rate: 1979-1982." Federal Reserve Bank of Richmond Economic Review (January/February 1989): 3-19.

Del Negro, Marco, Marc P. Giannoni, and Frank Schorfheide. "Inflation in the Great Recession and New Keynesian Models." American Economic Journal: Macroeconmomics 7 (January 2015): 168-196.

Dong, Feng and Yi Wen. "Optimal Monetary Policy under Negative Interest Rate." Working Paper 2017-019A. St. Louis: Federal Reserve Bank of St. Louis, May 2017.

Duca, John V. "Financial Technology Shocks and the Case of the Missing M2." Journal of Money, Credit, and Banking 32 (November 2000, Part 1): 820-839.

Durbin, J. and S.J. Koopman. "A Simple and Efficient Simulation Smoother for State Space Time Series Analysis." Biometrika 89 (September 2002): 603-615. 
Edge, Rochelle M. and Refet S. Gurkaynak. "How Useful Are Estimated DSGE Model Forecasts for Central Bankers?" Brookings Papers on Economic Activity (Fall 2010): 209-244.

Friedman, Milton. "The Role of Monetary Policy." American Economic Review 58 (March 1968): 1-17.

Galí, Jordi. Monetary Policy, Inflation, and the Business Cycle, 2nd Ed. Princeton: Princeton University Press, 2015.

Greenspan, Alan. "Remarks by Chairman Alan Greenspan: Rules vs. Discretionary Monetary Policy." Speech at the 15th Anniversary Conference of the Center for Economic Policy Research. Stanford: Stanford University, 5 September 1997.

Guerrieri, Luca and Matteo Iacoviello. "OccBin: A Toolkit for Solving Dynamic Models with Occasionally Binding Constraints Easily." Journal of Monetary Economics 70 (March 2015): 22-38.

Hallman, Jeffrey J., Richard D. Porter, and David H. Small. "Is the Price Level Tied to the M2 Monetary Aggregate in the Long-Run?" American Economic Review 81 (September 1991): 841-858.

Ireland, Peter N. "The Role of Countercyclical Monetary Policy." Journal of Political Economy 104 (August 1996): 704-723.

Ireland, Peter N. "Interest Rates, Inflation, and Federal Reserve Policy Since 1980." Journal of Money, Credit, and Banking 32 (August 2000, Part 1): 417-434.

Ireland, Peter N. "Technology Shocks in the New Keynesian Model." Review of Economics and Statistics 86 (November 2004a): 923-936.

Ireland, Peter N. "Money's Role in the Monetary Business Cycle." Journal of Money, Credit, and Banking 36 (December 2004b): 969-983. 
Ireland, Peter N. "Changes in the Federal Reserve's Inflation Target: Causes and Consequences." Journal of Money, Credit, and Banking 39 (December 2007): 1851-1882.

Ireland, Peter N. "On the Welfare Cost of Inflation and the Recent Behavior of Money Demand." American Economic Review 99 (June 2009): 1040-1052.

Ireland, Peter N. "A New Keynesian Perspective on the Great Recession." Journal of Money, Credit, and Banking 43 (February 2011): 31-54.

Jackson, Harriet. "The International Experience with Negative Policy Rates." Staff Discussion Paper 2015-13. Ottawa: Bank of Canada, November 2015.

Judson, Ruth A., Bernd Schlusche, and Vivian Wong. "Demand for M2 at the Zero Lower Bound: The Recent U.S. Experience." Finance and Economics Discussion Series 201422. Washington: Federal Reserve Board, January 2014.

King, Robert G., Charles I. Plosser, and Sergio T. Rebelo. "Production, Growth and Business Cycles: I. The Basic Neoclassical Model." Journal of Monetary Economics 21 (March-May 1988): 195-232.

Kulish, Mariano, James Morley, and Tim Robinson. "Estimating DSGE Models with Zero Interest Rate Policy." Journal of Monetary Economics 88 (June 2017): 35-49.

Meulendyke, Ann-Marie. U.S. Monetary Policy and Financial Markets. New York: Federal Reserve Bank of New York, 1998.

Nelson, Edward. "Direct Effects of Base Money on Aggregate Demand: Theory and Evidence." Journal of Monetary Economics 49 (May 2002): 687-708.

Orphanides, Athanasios and Richard D. Porter. "P* Revisited: Money-Based Inflation Forecasts with a Changing Equilibrium Velocity." Journal of Economics and Business 52 (January-April 2000): 87-100. 
Poole, William. "Optimal Choice of Monetary Policy Instruments in a Simple Stochasic Macro Model." Quarterly Journal of Economics 84 (May 1970): 197-216.

Rognlie, Matthew. "What Lower Bound? Monetary Policy with Negative Interest Rates." Manuscript. Evanston: Northwestern University, July 2016.

Rotemberg, Julio J. "Sticky Prices in the United States." Journal of Political Economy 90 (December 1982): 1187-1211.

Serletis, Apostolos and Periklis Gogas. "Divisia Monetary Aggregates, the Great Ratios, and Classical Money Demand Functions." Journal of Money, Credit, and Banking 46 (February 2014): 229-241.

Smets, Frank and Rafael Wouters. "Shocks and Frictions in US Business Cycles: A Bayesian DSGE Approach." American Economic Review 97 (June 2007): 586-606.

Swanson, Eric T. and John C. Williams. "Measuring the Effect of the Zero Lower Bound on Medium- and Longer-Term Interest Rates." American Economic Review 104 (October 2014): 3154-3185.

Taylor, John B. "Discretion Versus Policy Rules in Practice." Carnegie-Rochester Conference Series on Public Policy 39 (December 1993): 195-124.

Taylor, John B. Monetary Policy Rules. Chicago: University of Chicago Press, 1999.

Thornton, Daniel L. "When Did the FOMC Begin Targeting the Federal Funds Rate? What the Verbatim Transcripts Tell Us." Journal of Money, Credit, and Banking 38 (December 2006): 2039-2071.

Woodford, Michael. Interest and Prices: Foundations of a Theory of Monetary Policy. Princeton: Princeton University Press, 2003. 
Table 1. Prior Distributions for Structural Parameters

\begin{tabular}{lcccc}
\hline \hline & & & & Standard \\
Parameter & & Distribution & Mean & Deviation \\
\hline Habit Formation & $\alpha$ & Beta & 0.5 & 0.2 \\
Price Indexation & Beta & 0.5 & 0.2 \\
Phillips Curve Slope & $\psi$ & Gamma & 0.1 & 0.03 \\
Money Demand Semi-Elasticity & $\delta_{r}$ & Gamma & 5 & 5 \\
Money Demand Adjustment Cost & $\phi$ & Gamma & 10 & 10 \\
Interest Rate Smoothing & $\rho_{r}$ & Beta & 0.75 & 0.1 \\
Policy Response to Inflation & $\rho_{\pi}$ & Gamma & 0.4 & 0.1 \\
Policy Response to Output Gap & $\rho_{x}$ & Gamma & 0.2 & 0.1 \\
Preference Shock Persistence & $\rho_{a}$ & Beta & 0.75 & 0.1 \\
Money Demand Shock Persistence & $\rho_{u}$ & Beta & 0.75 & 0.1 \\
Cost Push Shock Persistence & $\rho_{e}$ & Beta & 0.5 & 0.1 \\
Preference Shock Volatility & $\sigma_{a}$ & Inverse Chi-squared & 0.0125 & 0.0066 \\
Productivity Shock Volatility & $\sigma_{z}$ & Inverse Chi-squared & 0.0125 & 0.0066 \\
Money Demand Shock Volatility & $\sigma_{u}$ & Inverse Chi-squared & 0.0125 & 0.0066 \\
Cost Push Shock Volatility & $\sigma_{e}$ & Inverse Chi-squared & 0.0031 & 0.0016 \\
Monetary Policy Shock Volatility & $\sigma_{r}$ & Inverse Chi-squared & 0.0031 & 0.0016 \\
\hline \hline
\end{tabular}

Note: Prior distributions for the standard deviations $\sigma_{i}, i=a, z, u, e, r$, are those induced by assuming that the associated variance $\sigma_{i}^{2}$ has the inverse chi-squared distribution with scale parameter $0.01^{2}$ for $i=a, z, u$ or $0.0025^{2}$ for $i=e, r$ and 4 degrees of freedom. 
Table 2. Posterior Distributions for Structural Parameters

\begin{tabular}{lcccccc}
\hline \hline & & & & & \multicolumn{2}{c}{ Percentile } \\
Parameter & & Mean & Mode & Median & 16 & 84 \\
\hline Habit Formation & $\gamma$ & 0.6779 & 0.6770 & 0.6798 & 0.6269 & 0.7285 \\
Price Indexation & $\alpha$ & 0.2380 & 0.2295 & 0.2332 & 0.1420 & 0.3339 \\
Phillips Curve Slope & $\psi$ & 0.0191 & 0.0169 & 0.0183 & 0.0133 & 0.0249 \\
Money Demand Semi-Elasticity & $\delta_{r}$ & 13.5990 & 13.0500 & 13.3850 & 10.6580 & 16.5332 \\
Money Demand Adjustment Cost & $\phi$ & 13.7459 & 11.1000 & 12.8717 & 9.1899 & 18.1903 \\
Interest Rate Smoothing & $\rho_{r}$ & 0.8335 & 0.8375 & 0.8354 & 0.7963 & 0.8706 \\
Policy Response to Inflation & $\rho_{\pi}$ & 0.2335 & 0.2270 & 0.2306 & 0.1906 & 0.2765 \\
Policy Response to Output Gap & $\rho_{x}$ & 0.2394 & 0.2150 & 0.2322 & 0.1805 & 0.2984 \\
Preference Shock Persistence & $\rho_{a}$ & 0.9235 & 0.9292 & 0.9246 & 0.9052 & 0.9417 \\
Money Demand Shock Persistence & $\rho_{u}$ & 0.9731 & 0.9778 & 0.9751 & 0.9617 & 0.9847 \\
Cost Push Shock Persistence & $\rho_{e}$ & 0.3295 & 0.3370 & 0.3300 & 0.2607 & 0.3981 \\
Preference Shock Volatility & $\sigma_{a}$ & 0.0402 & 0.0379 & 0.0394 & 0.0338 & 0.0466 \\
Productivity Shock Volatility & $\sigma_{z}$ & 0.0117 & 0.0112 & 0.0116 & 0.0101 & 0.0134 \\
Money Demand Shock Volatility & $\sigma_{u}$ & 0.0237 & 0.0209 & 0.0226 & 0.0186 & 0.0285 \\
Cost Push Shock Volatility & $\sigma_{e}$ & 0.0013 & 0.0013 & 0.0013 & 0.0012 & 0.0015 \\
Monetary Policy Shock Volatility & $\sigma_{r}$ & 0.0010 & 0.0010 & 0.0010 & 0.0009 & 0.0011 \\
\hline \hline
\end{tabular}


Table 3. Counterfactual Simulations

\begin{tabular}{lccccccccc}
\hline \hline & \multicolumn{3}{c}{ Estimated } & \multicolumn{3}{c}{ Money Growth Rule } & \multicolumn{3}{c}{ Constant Money Growth } \\
Standard Deviation of & Median & 16 & 84 & Median & 16 & 84 & Median & 16 & 84 \\
\hline Output Growth & 0.6032 & 0.6032 & 0.6032 & 0.6496 & 0.6259 & 0.6826 & 0.9194 & 0.8386 & 1.0253 \\
Inflation & 0.2451 & 0.2451 & 0.2451 & 0.2572 & 0.2336 & 0.2919 & 0.4132 & 0.3703 & 0.4600 \\
Nominal Interest Rate & 0.7131 & 0.7131 & 0.7131 & 0.6149 & 0.5667 & 0.6690 & 0.5006 & 0.4452 & 0.5716 \\
Money Growth Rate & 0.7479 & 0.7479 & 0.7479 & 0.5489 & 0.5156 & 0.5841 & 0.0000 & 0.0000 & 0.0000 \\
Output Gap & 0.7311 & 0.5716 & 0.9192 & 0.7967 & 0.7056 & 0.8989 & 2.4659 & 2.0456 & 2.9700 \\
\hline \hline
\end{tabular}

Note: The table shows the median and the 16th and 84th percentiles of the posterior distribution for the historical standard deviation of the indicated variable under the estimated policy rule, the flexible money growth rule (34) described in the text, and constant money growth 

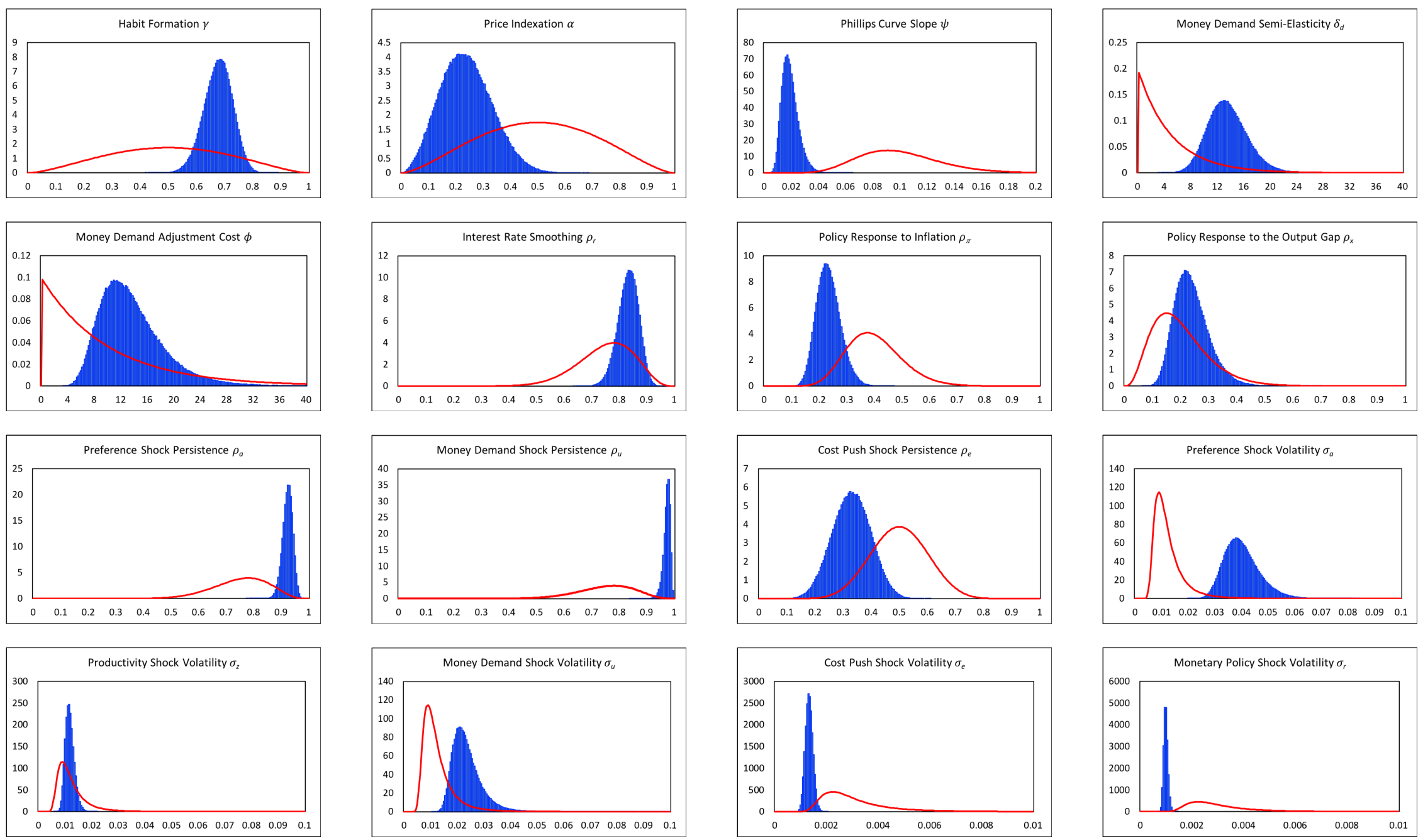

Figure 1. Prior and Posterior Densities, Structural Parameters. Each panel shows the prior (red line) and posterior (blue bars) density of the indicated structural parameter. 

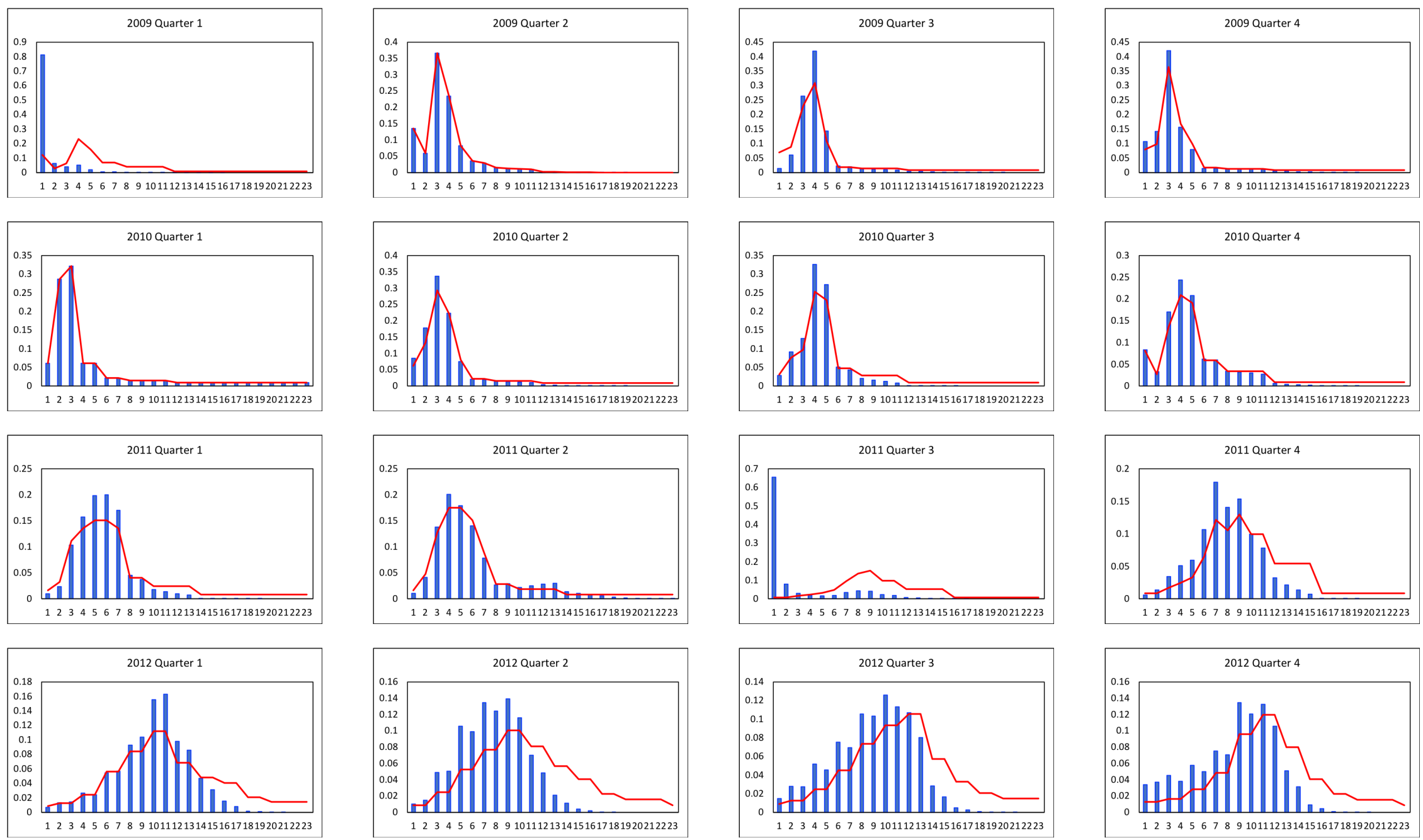

Figure 2. Prior and Posterior Densities, Expected Zero Nominal Interest Rate Episode. Each panel shows the prior (red line) and posterior (blue bars) density of the expected duration of the zero nominal interest rate episode at the indicated date. 

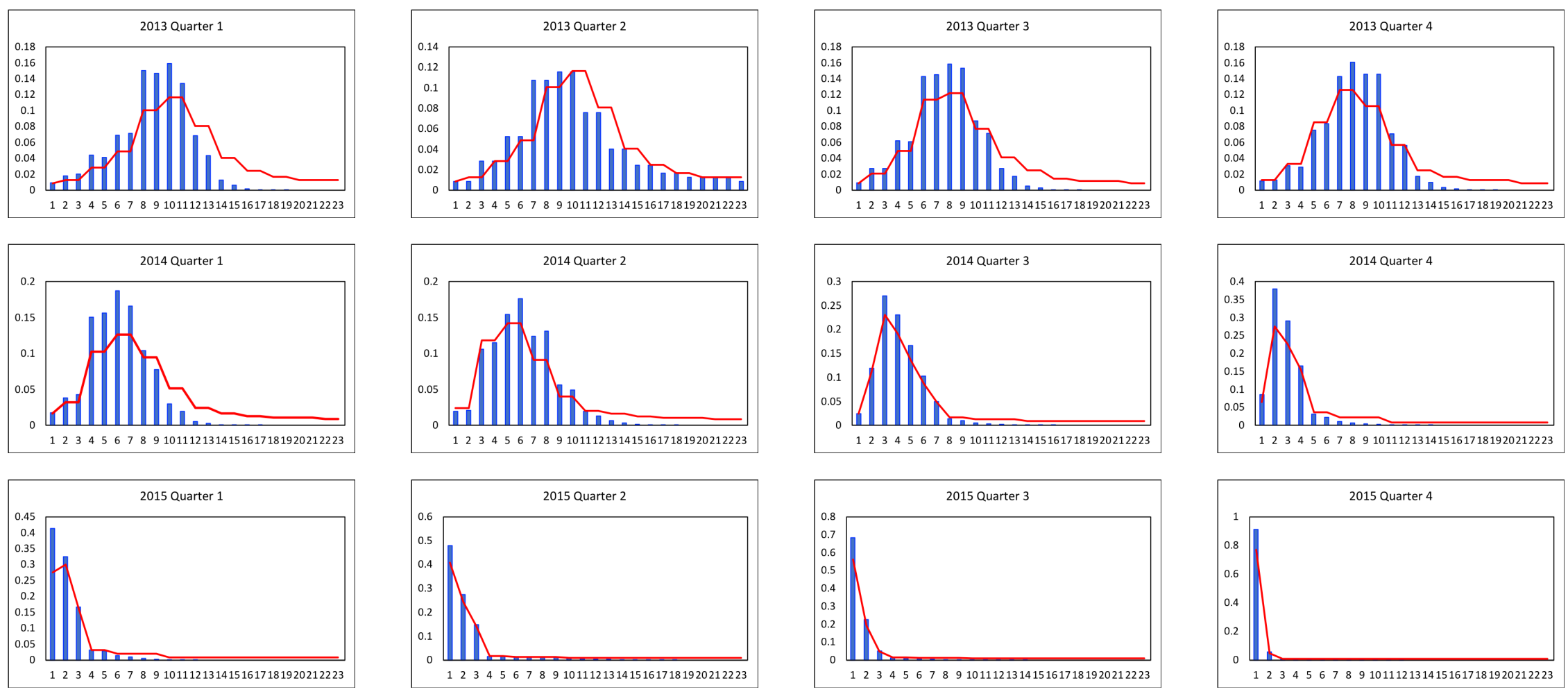

Figure 3. Prior and Posterior Densities, Expected Zero Nominal Interest Rate Episode. Each panel shows the prior (red line) and posterior (blue bars) density of the expected duration of the zero nominal interest rate episode at the indicated date. 

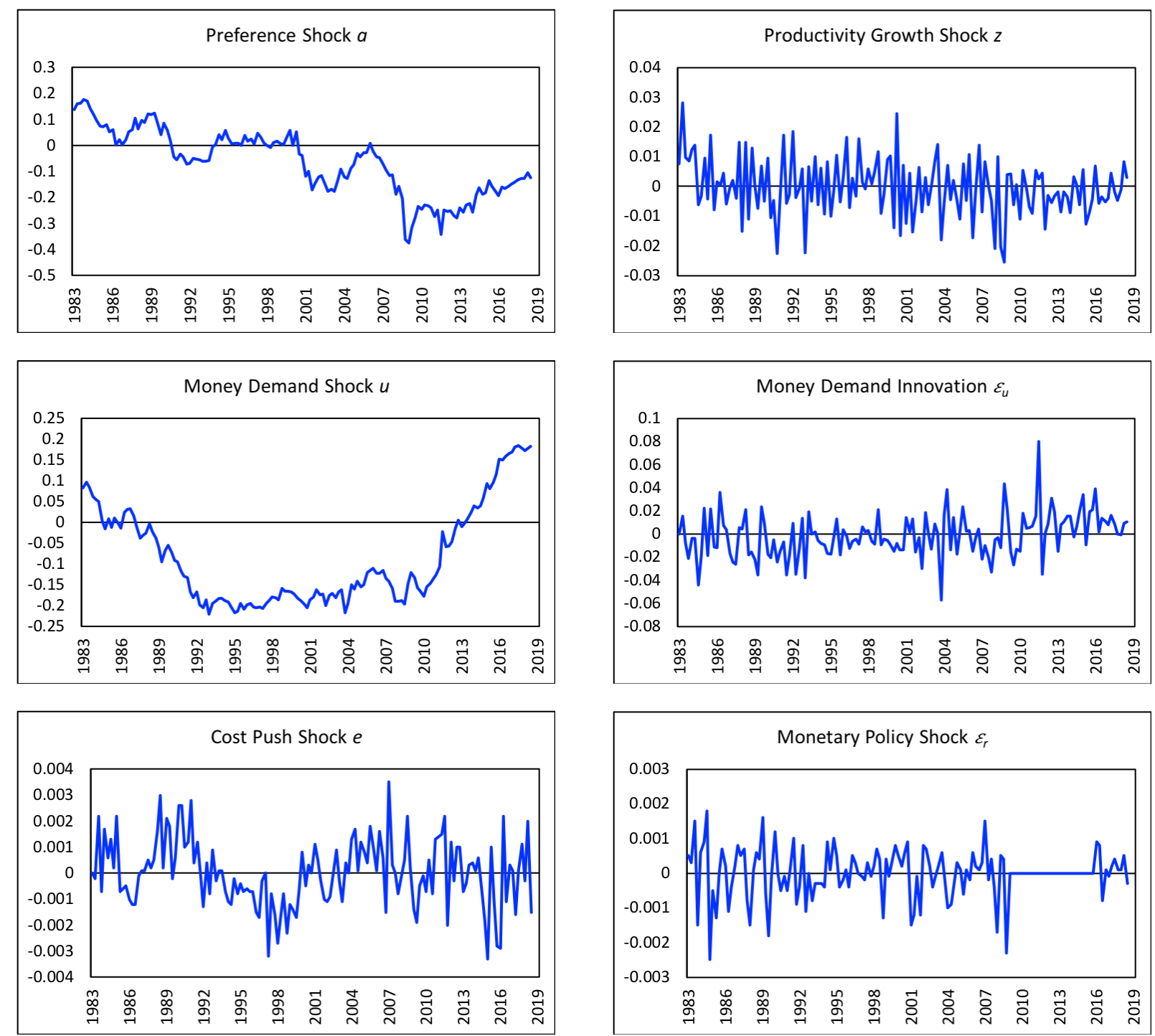

Figure 4. Estimated Structural Shocks. Each panel shows the median path from the posterior distribution of the indicated structural shock. 

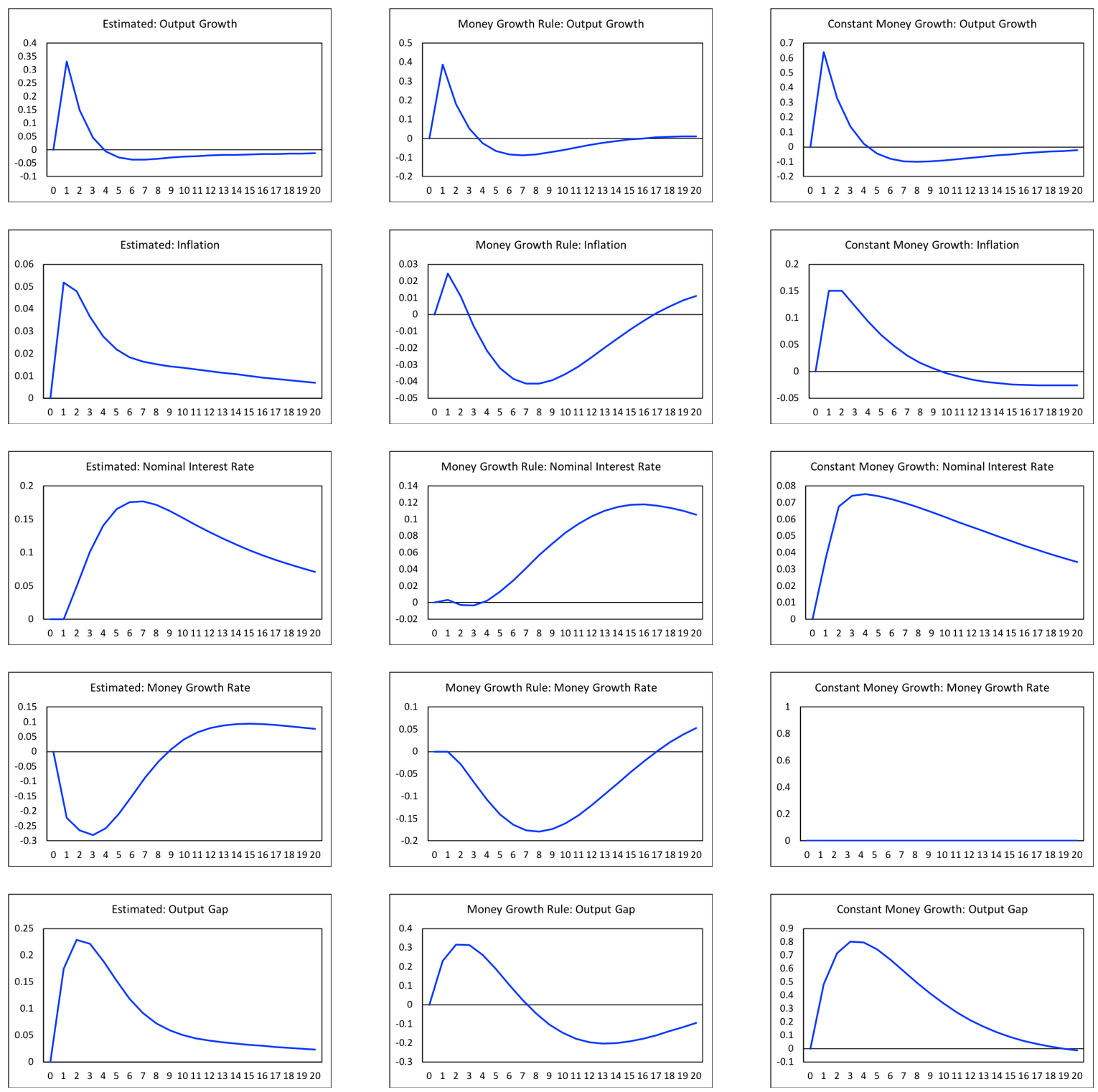

Figure 5. Impulse Responses to a Preference Shock. Each panel shows the percentage-point response of the indicated variable to a one-standard-deviation preference shock under the estimated policy rule, the flexible money growth rule (34) described in the text, and constant money growth, when the parameters of the structural model are set equal to their posterior modes. 

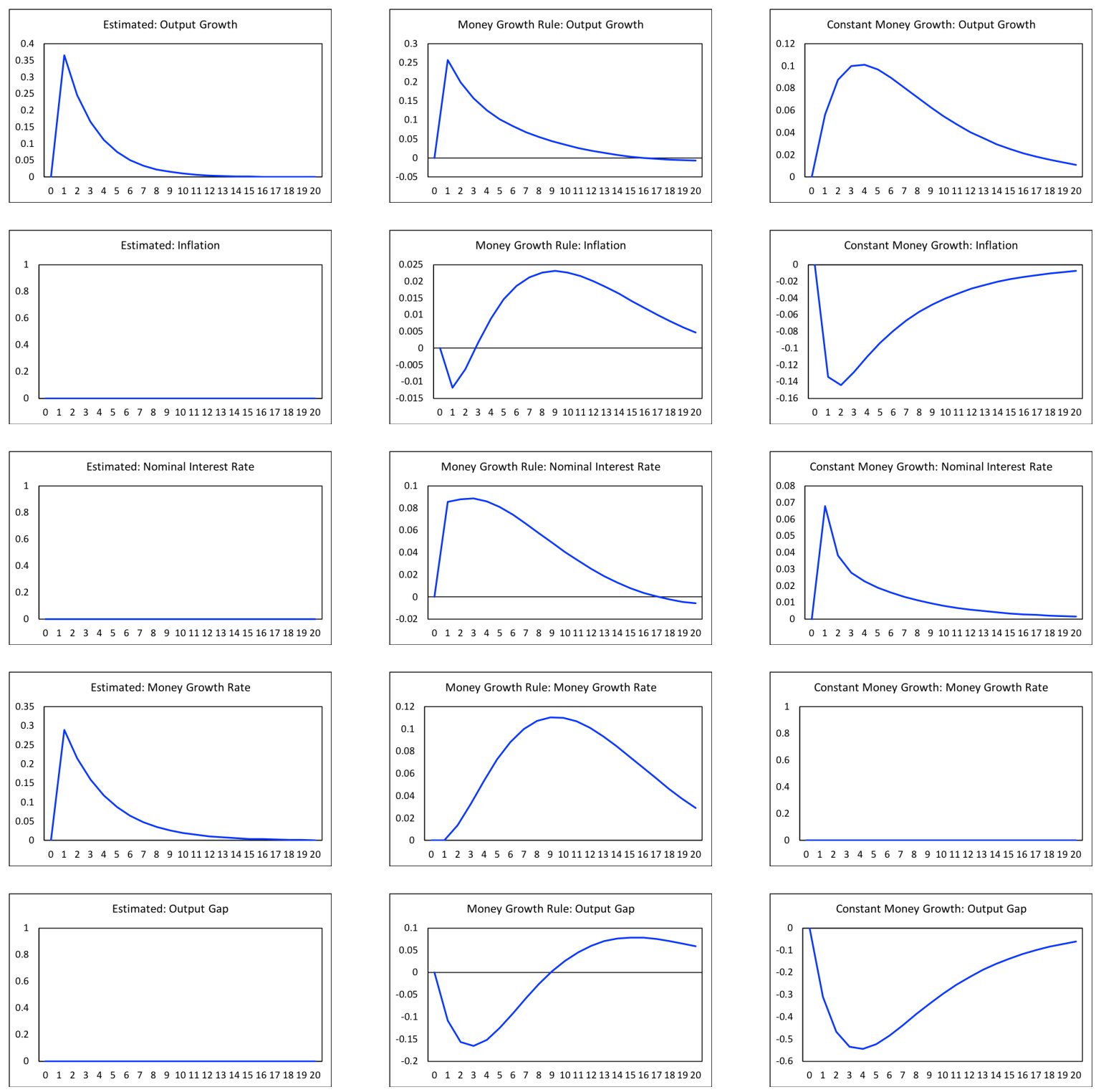

Figure 6. Impulse Responses to a Productivity Shock. Each panel shows the percentage-point response of the indicated variable to a one-standard-deviation productivity shock under the estimated policy rule, the flexible money growth rule (34) described in the text, and constant money growth, when the parameters of the structural model are set equal to their posterior modes. 

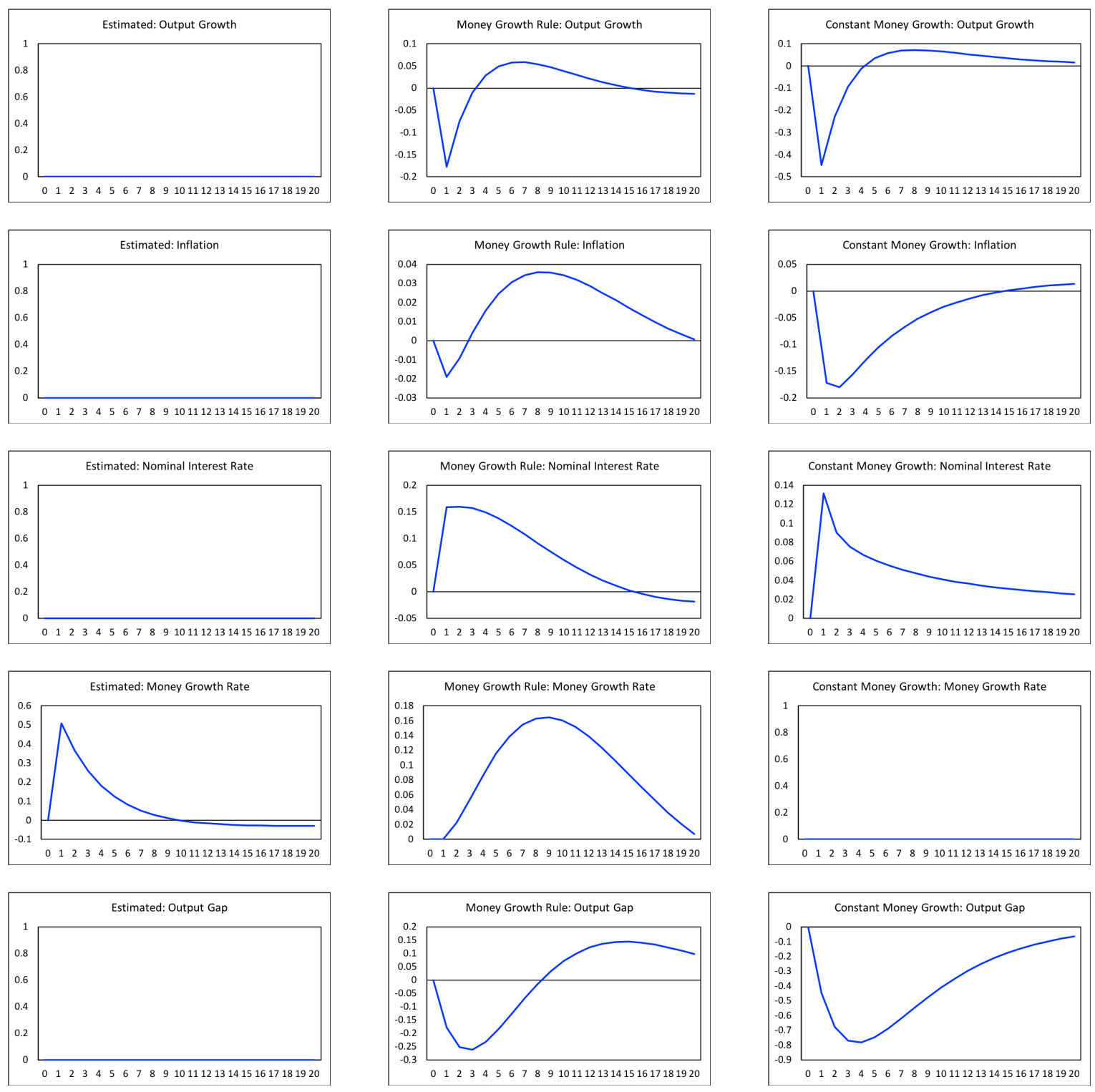

Figure 7. Impulse Responses to a Money Demand Shock. Each panel shows the percentagepoint response of the indicated variable to a one-standard-deviation productivity shock under the estimated policy rule, the flexible money growth rule (34) described in the text, and constant money growth, when the parameters of the structural model are set equal to their posterior modes. 

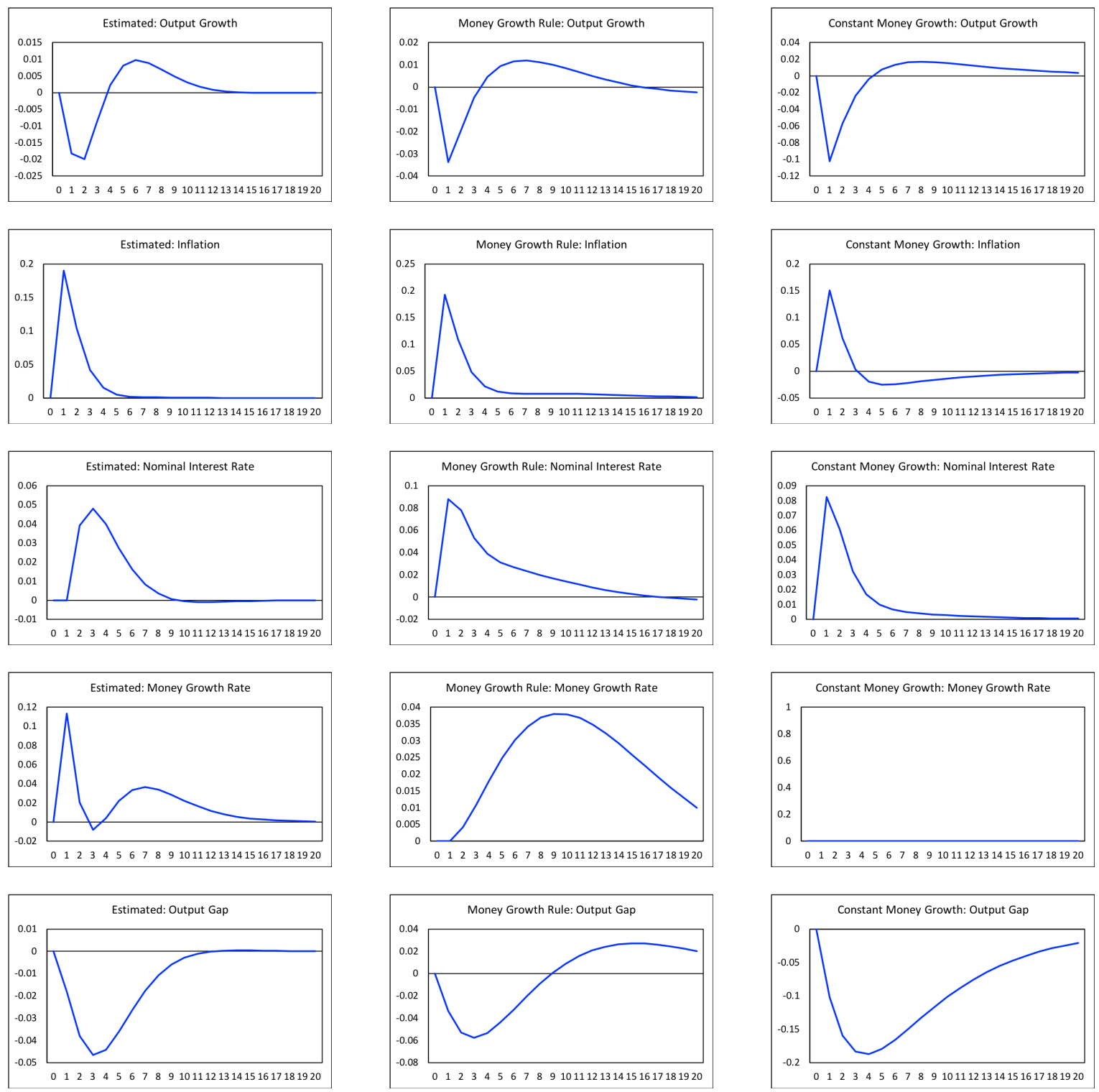

Figure 8. Impulse Responses to a Cost Push Shock. Each panel shows the percentagepoint response of the indicated variable to a one-standard-deviation cost push shock under the estimated policy rule, the flexible money growth rule (34) described in the text, and constant money growth, when the parameters of the structural model are set equal to their posterior modes. 

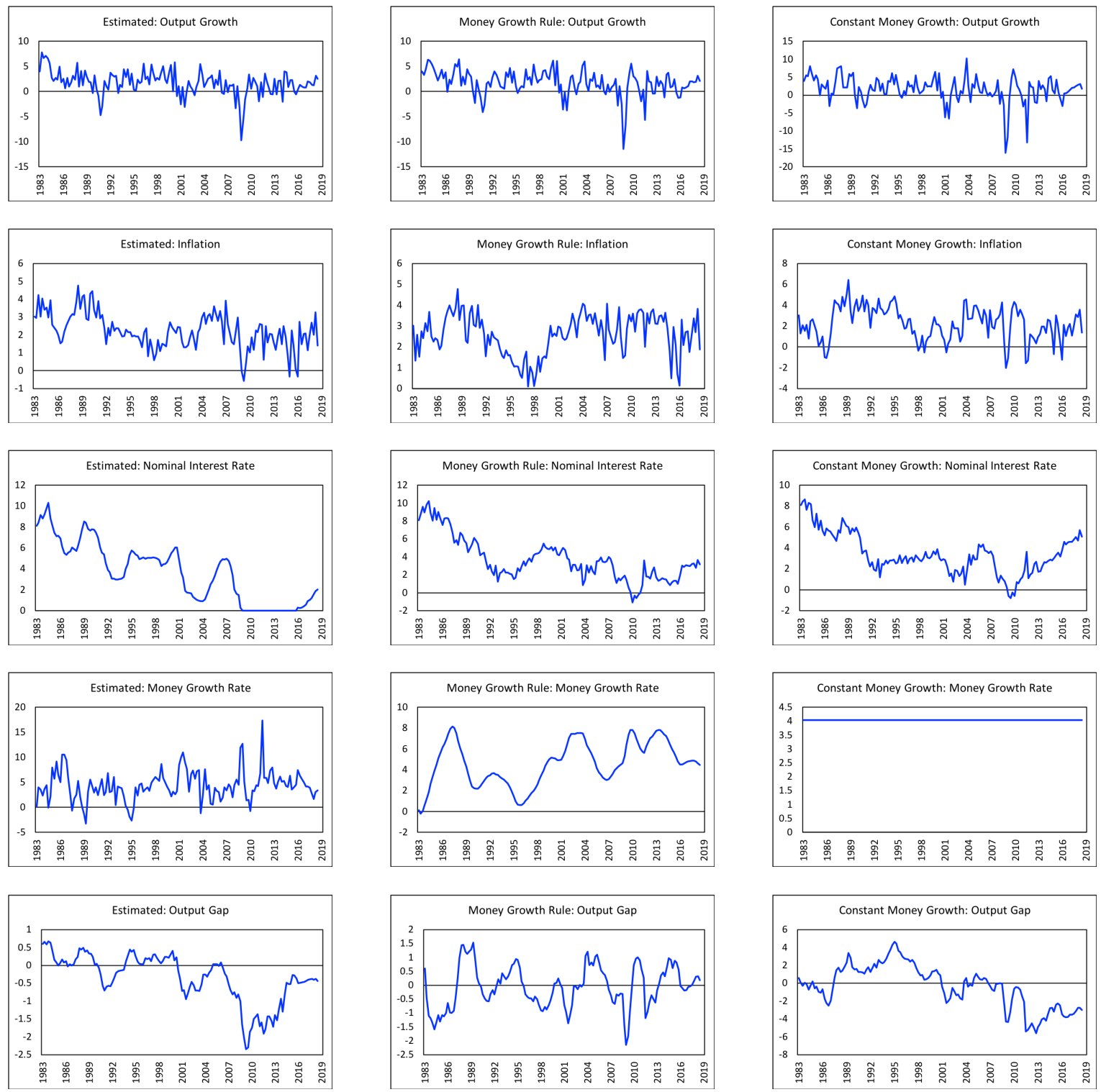

Figure 9. Counterfactual Simulations. Panels in the first column show the actual path for output growth, inflation, the nominal interest rate, and the money growth rate, all in annualized terms, and the median path from the estimated posterior distribution of the output gap. Panels in the second and third columns show median counterfactual paths from the estimated posterior distribution of the same variables under the flexible money growth rule (34) described in the text and constant money growth. 


\section{Appendix}

\subsection{Deriving the Log-Linearized Model}

After imposing the symmetry and market clearing conditions $Y_{t}(i)=Y_{t}, h_{t}(i)=h_{t}, D_{t}(i)=$ $D_{t}$, and $P_{t}(i)=P_{t}$ for all $i \in[0,1]$ and $t=0,1,2, \ldots$ and $M_{t}=M_{t-1}+T_{t}$ and $B_{t}=B_{t-1}=0$ for all $t=0,1,2, \ldots,(6),(11)$, and (12) can be used to solve out for $W_{t} / P_{t}, h_{t}$, and $D_{t}$. The system implied by (1)-(5), (7), (9), (10), and (13)-(18) then becomes

$$
\begin{aligned}
& Y_{t}=C_{t}+\frac{\phi_{p}}{2}\left(\frac{\pi_{t}}{\pi_{t-1}^{\alpha} \pi^{1-\alpha}}-1\right)^{2} Y_{t} \\
& \ln \left(a_{t}\right)=\rho_{a} \ln \left(a_{t-1}\right)+\varepsilon_{a t}, \\
& \ln \left(Z_{t}\right)=\ln (z)+\ln \left(Z_{t-1}\right)+\varepsilon_{z t}, \\
& \ln \left(u_{t}\right)=\rho_{u} \ln \left(u_{t-1}\right)+\varepsilon_{u t}, \\
& \Lambda_{t}=\frac{a_{t}}{C_{t}-\gamma C_{t-1}}-\beta \gamma E_{t}\left(\frac{a_{t+1}}{C_{t+1}-\gamma C_{t}}\right) \text {, } \\
& \Lambda_{t}=\beta r_{t} E_{t}\left(\Lambda_{t+1} / \pi_{t+1}\right), \\
& \frac{a_{t}}{\delta}\left[\ln \left(m^{*}\right)-\ln \left(\frac{M_{t}}{P_{t} Z_{t}}\right)+\ln \left(u_{t}\right)\right]-a_{t}\left(\frac{\phi_{m}}{2}\right)\left(\frac{M_{t} / P_{t}}{z M_{t-1} / P_{t-1}}-1\right)^{2} \\
& -a_{t} \phi_{m}\left(\frac{M_{t} / P_{t}}{z M_{t-1} / P_{t-1}}-1\right)\left(\frac{M_{t} / P_{t}}{z M_{t-1} / P_{t-1}}\right) \\
& +\beta \phi_{m} E_{t}\left[a_{t+1}\left(\frac{M_{t+1} / P_{t+1}}{z M_{t} / P_{t}}-1\right)\left(\frac{M_{t+1} / P_{t+1}}{z M_{t} / P_{t}}\right)^{2}\left(\frac{z Z_{t}}{Z_{t+1}}\right)\right] \\
& =Z_{t} \Lambda_{t}\left(1-\frac{1}{r_{t}}\right) \\
& \ln \left(\theta_{t}\right)=\left(1-\rho_{\theta}\right) \ln (\theta)+\rho_{\theta} \ln \left(\theta_{t-1}\right)+\varepsilon_{\theta t}, \\
& \theta_{t}-1=\theta_{t}\left(\frac{a_{t}}{\Lambda_{t} Z_{t}}\right)-\phi_{p}\left(\frac{\pi_{t}}{\pi_{t-1}^{\alpha} \pi^{1-\alpha}}-1\right)\left(\frac{\pi_{t}}{\pi_{t-1}^{\alpha} \pi^{1-\alpha}}\right) \\
& +\beta \phi_{p} E_{t}\left[\left(\frac{\Lambda_{t+1} Y_{t+1}}{\Lambda_{t} Y_{t}}\right)\left(\frac{\pi_{t+1}}{\pi_{t}^{\alpha} \pi^{1-\alpha}}-1\right)\left(\frac{\pi_{t+1}}{\pi_{t}^{\alpha} \pi^{1-\alpha}}\right)\right], \\
& \frac{1}{Z_{t}}=\frac{1}{Q_{t}-\gamma Q_{t-1}}-\beta \gamma E_{t}\left[\left(\frac{a_{t+1}}{a_{t}}\right)\left(\frac{1}{Q_{t+1}-\gamma Q_{t}}\right)\right] \text {, } \\
& x_{t}=Y_{t} / Q_{t}, \\
& \ln \left(r_{t} / r\right)=\rho_{r} \ln \left(r_{t-1} / r\right)+\rho_{\pi} \ln \left(\pi_{t-1} / \pi\right)+\rho_{x} \ln \left(x_{t-1} / x\right)+\varepsilon_{r t}, \\
& \mu_{t}=\left(\frac{M_{t} / P_{t}}{M_{t-1} / P_{t-1}}\right) \pi_{t}
\end{aligned}
$$


and

$$
g_{t}=Y_{t} / Y_{t-1}
$$

for all $t=0,1,2, \ldots$

In terms of the stationary variables $y_{t}=Y_{t} / Z_{t}, c_{t}=C_{t} / Z_{t}, \pi_{t}, r_{t}, m_{t}=\left(M_{t} / P_{t}\right) / Z_{t}$, $q_{t}=Q_{t} / Z_{t}, x_{t}, \mu_{t}, g_{t}, \lambda_{t}=Z_{t} \Lambda_{t}, a_{t}, z_{t}=Z_{t} / Z_{t-1}, u_{t}$, and $\theta_{t}$, the system of symmetric equilibrium conditions can be rewritten as

$$
\begin{aligned}
& y_{t}=c_{t}+\frac{\phi_{p}}{2}\left(\frac{\pi_{t}}{\pi_{t-1}^{\alpha} \pi^{1-\alpha}}-1\right)^{2} y_{t} \\
& \ln \left(a_{t}\right)=\rho_{a} \ln \left(a_{t-1}\right)+\varepsilon_{a t}, \\
& \ln \left(z_{t}\right)=\ln (z)+\varepsilon_{z t}, \\
& \ln \left(u_{t}\right)=\rho_{u} \ln \left(u_{t-1}\right)+\varepsilon_{u t}, \\
& \lambda_{t}=\frac{a_{t} z_{t}}{z_{t} c_{t}-\gamma c_{t-1}}-\beta \gamma E_{t}\left(\frac{a_{t+1}}{z_{t+1} c_{t+1}-\gamma c_{t}}\right), \\
& \lambda_{t}=\beta r_{t} E_{t}\left(\frac{\lambda_{t+1}}{z_{t+1} \pi_{t+1}}\right) \text {, } \\
& \frac{a_{t}}{\delta}\left[\ln \left(m^{*}\right)-\ln \left(m_{t}\right)+\ln \left(u_{t}\right)\right]-a_{t}\left(\frac{\phi_{m}}{2}\right)\left(\frac{z_{t} m_{t}}{z m_{t-1}}-1\right)^{2} \\
& -a_{t} \phi_{m}\left(\frac{z_{t} m_{t}}{z m_{t-1}}-1\right)\left(\frac{z_{t} m_{t}}{z m_{t-1}}\right) \\
& +\beta \phi_{m} E_{t}\left[a_{t+1}\left(\frac{z_{t+1} m_{t+1}}{z m_{t}}-1\right)\left(\frac{z_{t+1} m_{t+1}}{z m_{t}}\right)^{2}\left(\frac{z}{z_{t+1}}\right)\right] \\
& =\lambda_{t}\left(1-\frac{1}{r_{t}}\right) \text {, } \\
& \ln \left(\theta_{t}\right)=\left(1-\rho_{\theta}\right) \ln (\theta)+\rho_{\theta} \ln \left(\theta_{t-1}\right)+\varepsilon_{\theta t}, \\
& \theta_{t}-1=\theta_{t}\left(\frac{a_{t}}{\lambda_{t}}\right)-\phi_{p}\left(\frac{\pi_{t}}{\pi_{t-1}^{\alpha} \pi^{1-\alpha}}-1\right)\left(\frac{\pi_{t}}{\pi_{t-1}^{\alpha} \pi^{1-\alpha}}\right) \\
& +\beta \phi_{p} E_{t}\left[\left(\frac{\lambda_{t+1} y_{t+1}}{\lambda_{t} y_{t}}\right)\left(\frac{\pi_{t+1}}{\pi_{t}^{\alpha} \pi^{1-\alpha}}-1\right)\left(\frac{\pi_{t+1}}{\pi_{t}^{\alpha} \pi^{1-\alpha}}\right)\right], \\
& 1=\frac{z_{t}}{z_{t} q_{t}-\gamma q_{t-1}}-\beta \gamma E_{t}\left[\left(\frac{a_{t+1}}{a_{t}}\right)\left(\frac{1}{z_{t+1} q_{t+1}-\gamma q_{t}}\right)\right], \\
& x_{t}=y_{t} / q_{t}, \\
& \ln \left(r_{t} / r\right)=\rho_{r} \ln \left(r_{t-1} / r\right)+\rho_{\pi} \ln \left(\pi_{t-1} / \pi\right)+\rho_{x} \ln \left(x_{t-1} / x\right)+\varepsilon_{r t}, \\
& \mu_{t}=z_{t}\left(m_{t} / m_{t-1}\right) \pi_{t},
\end{aligned}
$$

and

$$
g_{t}=\left(y_{t} / y_{t-1}\right) z_{t}
$$


for all $t=0,1,2, \ldots$

The stationary system pins down the steady-state values $y_{t}=y, c_{t}=c, \pi_{t}=\pi, r_{t}=r$, $m_{t}=m, q_{t}=q, x_{t}=x, \mu_{t}=\mu, g_{t}=g, \lambda_{t}=\lambda, a_{t}=a=1, z_{t}=z, u_{t}=u=1$, and $\theta_{t}=\theta$. In particular, $a=1, z, u=1$, and $\theta$ are determined exogenously by (2)-(4) and (10), and $\pi$ is chosen by the central bank through (16). Equations (1), (17), and (18) then imply that $c=y, g=z$, and $\mu=z \pi$. Equation (13) implies that

$$
\lambda=\theta /(\theta-1) .
$$

Equation (5) then implies that

$$
y=\left(\frac{\theta-1}{\theta}\right)\left(\frac{z-\beta \gamma}{z-\gamma}\right)
$$

Equation (14) implies that

$$
q=\frac{z-\beta \gamma}{z-\gamma}
$$

so that (15) implies

$$
x=\frac{\theta-1}{\theta} .
$$

Equation (7) implies

$$
r=(z / \beta) \pi .
$$

Finally, (9) implies

$$
\ln (m)=\ln \left(m^{*}\right)-\delta_{r}(r-1),
$$

where

$$
\delta_{r}=\left(\frac{\delta}{r}\right)\left(\frac{\theta}{\theta-1}\right) .
$$

A log-linear approximation to (1) yields $\hat{c}_{t}=\hat{y}_{t}$. Log-linear approximations to the remaining 13 equations in the stationary system produce (19)-(31) in the text.

\subsection{Solving the Log-Linearized Model}

Let

$$
s_{0, t}=\left[\begin{array}{lllllllll}
\hat{y}_{t} & \hat{\pi}_{t} & \hat{r}_{t} & \hat{m}_{t} & \hat{g}_{t} & \hat{\mu}_{t} & \hat{q}_{t} & \hat{x}_{t} & \hat{\lambda}_{t}
\end{array}\right]^{\prime}
$$

and

$$
\xi_{t}=\left[\begin{array}{lllll}
\hat{a}_{t} & \hat{z}_{t} & \hat{u}_{t} & \hat{e}_{t} & \varepsilon_{r t}
\end{array}\right]^{\prime} .
$$

Then (20)-(27) can be written as

$$
A_{0} s_{0, t}=A_{1} s_{0, t-1}+B_{0} E_{t} s_{0, t+1}+C_{0} \xi_{t}
$$

where $A_{0}, A_{1}$, and $B_{0}$ are $9 \times 9$ matrices and $C_{0}$ is a $9 \times 5$ matrix, with elements determined by the model's structural parameters. After inverting $A_{0}$, (A.1) can be written in the slightly 
simpler form

$$
s_{0, t}=A s_{0, t-1}+B E_{t} s_{0, t+1}+C \xi_{t},
$$

where $A=A_{0}^{-1} A_{1}, B=A_{0}^{-1} B_{0}$, and $C=A_{0}^{-1} C_{0}$. Meanwhile, (28)-(31) can be written as

$$
\begin{gathered}
\xi_{t}=P \xi_{t-1}+\varepsilon_{t}, \\
P=\left[\begin{array}{cccccc}
\rho_{a} & 0 & 0 & 0 & 0 \\
0 & 0 & 0 & 0 & 0 \\
0 & 0 & \rho_{u} & 0 & 0 \\
0 & 0 & 0 & \rho_{e} & 0 \\
0 & 0 & 0 & 0 & 0
\end{array}\right]
\end{gathered}
$$

and

$$
\varepsilon_{t}=\left[\begin{array}{lllll}
\varepsilon_{a t} & \varepsilon_{z t} & \varepsilon_{u t} & \varepsilon_{e t} & \varepsilon_{r t}
\end{array}\right]^{\prime} .
$$

Following Binder and Pesaran (1985), decompose $s_{0, t}$ into "backward" and "forward" looking components:

$$
s_{0, t}=s_{b, t}+s_{f, t}=D s_{0, t-1}+s_{f, t},
$$

where $D$ is a $9 \times 9$ matrix to be determined. Substitute (A.4) into the left-hand side of (A.2) and

$$
E_{t} s_{0, t+1}=D s_{0, t}+E_{t} s_{f, t+1}=D^{2} s_{0, t-1}+D s_{f, t}+E_{t} s_{f, t+1}
$$

into the right-hand side of (A.2) to obtain

$$
\left[I_{(9 \times 9)}-B D\right] s_{f, t}=\left(B D^{2}-D+A\right) s_{0, t-1}+B E_{t} s_{f, t+1}+C \xi_{t} .
$$

Equation (A.5) reveals that for $s_{f, t}$ to be purely forward looking, $D$ must solve the second-order matrix polynomial equation

$$
B D^{2}-D+A=0_{(9 \times 9)}
$$

Once the solution for $D$ is in hand, (A.5) can be written more simply as

$$
s_{f, t}=F E_{t} s_{f, t+1}+G \xi_{t},
$$

where $F=\left[I_{(9 \times 9)}-B D\right]^{-1} B$ and $G=\left[I_{(9 \times 9)}-B D\right]^{-1} C$. Assuming all the eigenvalues of $F$ are inside the unit circle and using (A.3), (A.7) can be solved forward to obtain

$$
s_{f, t}=H \xi_{t}
$$

where the $9 \times 5$ matrix $H$ is determined by

$$
\operatorname{vec}(H)=\left[I_{(45 \times 45)}-\left(P^{\prime} \otimes F\right)\right]^{-1} \operatorname{vec}(G) .
$$

Substituting (A.8) into (A.4) now provides the solution

$$
s_{0, t}=D s_{0, t+1}+H \xi_{t}
$$


Finally, combining (A.4) and (A.9) yields

$$
s_{t+1}=\Pi s_{t}+W \varepsilon_{t+1},
$$

where

$$
\begin{aligned}
& s_{t}=\left[\begin{array}{ll}
s_{0, t}^{\prime} & \xi_{t}^{\prime}
\end{array}\right]^{\prime}=\left[\begin{array}{llllllllllllll}
\hat{y}_{t} & \hat{\pi}_{t} & \hat{r}_{t} & \hat{m}_{t} & \hat{g}_{t} & \hat{\mu}_{t} & \hat{q}_{t} & \hat{x}_{t} & \hat{\lambda}_{t} & \hat{a}_{t} & \hat{z}_{t} & \hat{u}_{t} & \hat{e}_{t} & \varepsilon_{r t}
\end{array}\right]^{\prime}, \\
& \Pi=\left[\begin{array}{cc}
D & H P \\
0_{(5 \times 9)} & P
\end{array}\right],
\end{aligned}
$$

and

$$
W=\left[\begin{array}{c}
H \\
I_{(5 \times 5)}
\end{array}\right] .
$$

It only remains to find the matrix $D$ that solves (A.6). To accomplish this task, start by rewriting (A.2) as

$$
K E_{t} s_{1, t+1}=L s_{1, t}+M \xi_{t}
$$

where

$$
\begin{gathered}
s_{1, t}=\left[\begin{array}{ll}
s_{0, t-1}^{\prime} & s_{0, t}^{\prime}
\end{array}\right]^{\prime}, \\
K=\left[\begin{array}{cc}
I_{(9 \times 9)} & 0_{(9 \times 9)} \\
0_{(9 \times 9)} & B
\end{array}\right], \\
L=\left[\begin{array}{cc}
0_{(9 \times 9)} & I_{(9 \times 9)} \\
-A & I_{(9 \times 9)}
\end{array}\right],
\end{gathered}
$$

and

$$
M=\left[\begin{array}{c}
0_{(9 \times 5)} \\
-C
\end{array}\right] .
$$

Higham and Kim (2000) and Lan and Meyer-Godhe (2012) show that $D$ can be found using the generalized Schur, or $Q Z$, decomposition, which identifies unitary matrices $Q$ and $Z$ such that

$$
Q K Z=S
$$

and

$$
Q L Z=T
$$

are both upper triangular, where the generalized eigenvalues of $L$ and $K$ can be recovered as the ratios of the diagonal elements on $T$ and $S$ :

$$
\lambda(L, K)=\left\{t_{i i} / s_{i i} \mid i=1,2, \ldots, 18\right\} .
$$

The matrices $Q, Z, S$, and $T$ can always be arranged so that the generalized eigenvalues appear in ascending order in absolute value. Note that, by design, there are nine "predetermined" or lagged values in the vector $s_{1, t}$. Thus, if nine of the generalized eigenvalues in $\lambda(L, K)$ lie inside the unit circle and nine of the generalized eigenvalues lie outside the unit circle, the system has a unique dynamically stable solution. If more than nine of the generalized eigenvalues in $\lambda(L, K)$ lie outside the unit circle, then the system has no stable 
solution; and if less than nine of the generalized eigenvalues lie outside the unit circle, then the system has multiple stable solutions. For details, see Blanchard and Kahn (1980) and Klein (2000).

Assuming that there are exactly nine generalized eigenvalues that lie outside the unit circle, partition the matrix $Z$ into $9 \times 9$ blocks:

$$
Z=\left[\begin{array}{ll}
Z_{11} & Z_{12} \\
Z_{21} & Z_{22}
\end{array}\right]
$$

Then, according to Higham and Kim (2000) and Lan and Meyer-Godhe (2012),

$$
D=Z_{21} Z_{11}^{-1}
$$

will be the unique solution to (A.6) with all of its eigenvalues inside the unit circle, and the matrix $F$ appearing in (A.7) will also have all of its eigenvalues inside the unit circle.

\subsection{Imposing Zero Nominal Interest Rates}

Kulish, Morley, and Robinson (2017) outline methods to solve and estimate the model over samples including the period from 2009:1 through 2015:4 when the Federal Reserve held short-term nominal interest rates in the US in a range near zero. Prior to and after the zero nominal interest rate period, the log-linearized model's solution is given by (A.10), as derived above. Let $t=T_{1}$ denote the start of the zero interest rate period, when the central bank replaces the Taylor rule (24) with the zero nominal interest rate condition (32). Then (32) can be combined with the remaining equilibrium conditions (19)-(23) and (24)-(31) to obtain

$$
\bar{A}_{0} s_{0, t}=\bar{J}_{0}+\bar{A}_{1} s_{0, t-1}+\bar{B}_{0} E_{t} s_{0, t+1}+\bar{C}_{0} \xi_{t},
$$

where the $9 \times 9$ matrices $\bar{A}_{0}, \bar{A}_{1}$, and $\bar{B}_{0}$ and the $9 \times 5$ matrix $\bar{C}_{0}$ coincide with $A_{0}, A_{1}$, $B_{0}$, and $C_{0}$ in (A.1), except that they replace with zeros the elements corresponding to the parameters of the Taylor rule (24), and the $9 \times 1$ vector $\bar{J}_{0}$ consists of zeros except for the term $-\ln (r)$ appearing in the row corresponding to the zero interest rate condition (32). After inverting $\bar{A}_{0}$, (A.13) can be written in the slightly simpler form

$$
s_{0, t}=\bar{J}+\bar{A} s_{0, t-1}+\bar{B} E_{t} s_{0, t+1}+\bar{C} \xi_{t},
$$

where $\bar{J}=\bar{A}_{0}^{-1} \bar{J}_{0}, \bar{A}=\bar{A}_{0}^{-1} \bar{A}_{1}, \bar{B}=\bar{A}_{0}^{-1} \bar{B}_{0}$, and $\bar{C}=\bar{A}_{0}^{-1} \bar{C}_{0}$.

During periods $t=T_{1}, T_{1}+1, \ldots, T_{2}=T_{1}+\tau-1$, while interest rates are held at zero, the solution for $s_{0, t}$ will follow the time-varying coefficient VAR

$$
s_{0, t}=J_{t}+D_{t} s_{0, t-1}+H_{t} \xi_{t}
$$

which implies that

$$
E_{t} s_{0, t+1}=J_{t+1}+D_{t+1} s_{0, t}+H_{t+1} P \xi_{t} .
$$


Substitute (A.16) into (A.14) to obtain

$$
s_{0, t}=\bar{J}+\bar{A} s_{0, t-1}+\bar{B} J_{t+1}+\bar{B} D_{t+1} s_{0, t}+\bar{B} H_{t+1} P \xi_{t}+\bar{C} \xi_{t} .
$$

Matching coefficients across (A.15) and (A.16) then yields

$$
\begin{gathered}
D_{t}=\left[I_{(9 \times 9)}-\bar{B} D_{t+1}\right]^{-1} \bar{A}, \\
H_{t}=\left[I_{(9 \times 9)}-\bar{B} D_{t+1}\right]^{-1}\left(\bar{C}+\bar{B} H_{t+1} P\right),
\end{gathered}
$$

and

$$
J_{t}=\left[I_{(9 \times 9)}-\bar{B} D_{t+1}\right]^{-1}\left(\bar{J}+\bar{B} J_{t+1}\right) .
$$

Starting from the terminal conditions $D_{T_{2}+1}=D$ and $H_{T_{2}+1}=H$, where $D$ is determined by (A.12) and $H$ by (A.8), and $J_{T_{2}+1}=0_{(9 \times 1)},($ A.18)-(A.20) can be solved via backward recursion for the sequences $\left\{D_{T_{1}+j}\right\}_{j=0}^{\tau-1},\left\{H_{T_{1}+j}\right\}_{j=0}^{\tau-1}$, and $\left\{J_{T_{1}+j}\right\}_{j=0}^{\tau-1}$, that appear in (A.15).

Still following Kulish, Morley, and Robinson (2017), assume more generally that the central bank re-evaluates the timing of its return to conventional policymaking via the Taylor rule (24) each period, announcing at the beginning of each time period $t$ that the zero nominal interest rate episode will continue for $\tau_{t}$ more periods. To keep track of outcomes in this case, let $\bar{\tau}$ be an arbitrarily large upper bound on the length of the zero interest rate episode, and re-label the subscripts on the matrices that solve (A.18)-(A.20) to that $\left\{D_{k}\right\}_{k=1}^{\bar{\tau}},\left\{H_{k}\right\}_{k=1}^{\bar{\tau}}$, and $\left\{J_{k}\right\}_{k=1}^{\bar{\tau}}$ are those that apply during any period when the zero interest rate episode is expected to last for $k$ more periods. Now, the matrices that appear in the solution (A.15) for the zero interest rate episode are given by $D_{t}=D_{\tau_{t}}, H_{t}=H_{\tau_{t}}$, and $J_{t}=J_{\tau_{t}}$. And, as noted above, the model's solution before and after the zero interest rate episode can be written in the same form, where $D_{t}=D, H_{t}=H$, and $J_{t}=0_{(9 \times 1)}$. Therefore, the solution for the model with the zero interest rate episode takes the form

$$
s_{t+1}=\nu_{t+1}+\Pi_{t+1} s_{t}+W_{t+1} \varepsilon_{t+1},
$$

where

$$
\begin{gathered}
\nu_{t+1}=\left[\begin{array}{c}
J_{t+1} \\
0_{(5 \times 1)}
\end{array}\right], \\
\Pi_{t+1}=\left[\begin{array}{cc}
D_{t+1} & H_{t+1} P \\
0_{(5 \times 9)} & P
\end{array}\right],
\end{gathered}
$$

and

$$
W_{t+1}=\left[\begin{array}{c}
H_{t+1} \\
I_{(5 \times 5)}
\end{array}\right] \text {. }
$$

\subsection{The Likelihood Function}

Evaluating the likelihood function and simulating the posterior distribution for the model, when estimated over a sample period that includes the zero nominal interest rate episode, is complicated by three factors. First, in addition to the structural parameters that enter into the New Keynesian model's equilibrium conditions (19)-(31), which can be collected into a 
vector $\Theta$, there is now a second set of parameters

$$
\Delta=\left\{\tau_{T_{1}}, \tau_{T_{1}+1}, \ldots, \tau_{T_{2}}\right\}
$$

for the expected duration of the zero interest rate episode at each period during that episode, starting at date $T_{1}$ and ending at $T_{2}$. This first complication will be dealt with as suggested by Kulish, Morley, and Robinson (2017) and described in more detail below. Second, because the short-term nominal interest rate has zero variance according to the zero interest rate condition (32), it must be removed from the list of observables during the zero interest rate episode. Thus, if $d_{t}$ denotes the vector of observable variables at each date $t=1,2, \ldots, T$ in the sample period,

$$
d_{t}=U_{t} s_{t}
$$

where, outside the zero interest rate episode, $U_{t}$ is $4 \times 16$ and formed from the selection vectors that pick out $\hat{g}_{t}, \hat{\pi}_{t}, \hat{r}_{t}$, and $\hat{\mu}_{t}$ from the state vector $s_{t}$ and, during the zero interest rate episode, $U_{t}$ is $3 \times 16$ and formed from the selection vectors that pick out just $\hat{g}_{t}, \hat{\pi}_{t}$, and $\hat{\mu}_{t}$ instead. Third, the matrices entering into the state-space model formed by (A.21) and (A.22) are time-varying. These last two complications can be accommodated within the standard Kalman filtering framework, as shown by Harvey (1989, Ch.3) and Anderson and Moore (2005, Ch.3), to evaluate the model's likelihood function $L\left(\left\{d_{t}\right\}_{t=1}^{T} \mid \Theta, \Delta\right)$.

In particular, let

$$
\hat{s}_{t}=E\left(s_{t} \mid d_{t-1}, d_{t-2}, \ldots, d_{1}\right)
$$

and

$$
\Sigma_{t}=E\left(s_{t}-\hat{s}_{t}\right)\left(s_{t}-\hat{s}_{t}\right)^{\prime} .
$$

Then, starting from the initial conditions implied by (A.10),

$$
\hat{s_{1}}=0_{(14 \times 1)}
$$

and

$$
\operatorname{vec}\left(\Sigma_{1}\right)=\left[I_{(196 \times 196)}-\Pi \otimes \Pi\right]^{-1} \operatorname{vec}\left(W V W^{\prime}\right),
$$

generate recursively the sequences

$$
\begin{gathered}
v_{t}=d_{t}-U_{t} \hat{s}_{t} \\
K_{t}=\Pi_{t+1} \Sigma_{t} U_{t}^{\prime}\left(U_{t} \Sigma_{t} U_{t}^{\prime}\right)^{-1}, \\
\hat{s}_{t+1}=\nu_{t+1}+\Pi_{t+1} \hat{s}_{t}+K_{t} v_{t},
\end{gathered}
$$

and

$$
\Sigma_{t+1}=W_{t+1} V W_{t+1}^{\prime}+\Pi_{t+1} \Sigma_{t} \Pi_{t+1}^{\prime}-\Pi_{t+1} \Sigma_{t} U_{t}^{\prime}\left(U_{t} \Sigma_{t} U_{t}^{\prime}\right)^{-1} U_{t} \Sigma_{t} \Pi_{t+1}^{\prime},
$$

where

$$
V=E \varepsilon_{t+1} \varepsilon_{t+1}^{\prime}=\left[\begin{array}{ccccc}
\sigma_{a}^{2} & 0 & 0 & 0 & 0 \\
0 & \sigma_{z}^{2} & 0 & 0 & 0 \\
0 & 0 & \sigma_{u}^{2} & 0 & 0 \\
0 & 0 & 0 & \sigma_{e}^{2} & 0 \\
0 & 0 & 0 & 0 & \sigma_{r}^{2}
\end{array}\right]
$$


is the covariance matrix of the New Keynesian model's structural shocks.

The innovations $\left\{v_{t}\right\}_{t=1}^{T}$ can then be used to evaluate likelihood function as

$$
\begin{aligned}
\ln \left(L\left(\left\{d_{t}\right\}_{t=1}^{T} \mid \Theta, \Delta\right)=\right. & -\left[\frac{4\left(T-T_{2}+T_{1}-1\right)+3\left(T_{2}-T_{1}+1\right)}{2}\right] \ln (2 \pi) \\
& -\frac{1}{2} \sum_{t=1}^{T} \ln \left(\left|U_{t} \Sigma_{t} U_{t}^{\prime}\right|\right)-\frac{1}{2} \sum_{t=1}^{T} v_{t}^{\prime}\left(U_{t} \Sigma_{t} U_{t}^{\prime}\right)^{-1} v_{t} .
\end{aligned}
$$

\subsection{Simulating the Posterior Distribution}

The log posterior kernel can be evaluated as

$$
\ln L\left(\left\{d_{t}\right\}_{t=1}^{T} \mid \Theta, \Delta\right)+\ln (P(\Theta, \Delta)),
$$

where $P(\Theta, \Delta)$ is the prior density over both sets of parameters. Kulish, Morley, and Robinson's (2017) modification of the randomized block Metropolis-Hastings algorithm of Chib and Ramamurthy (2010) is used to simulate draws from this posterior distribution. The algorithm treats $\Theta$ and $\Delta$ as separate blocks of parameters; this is natural, as $\Theta$ consists of continuously-valued structural parameters where as the durations in $\Delta$ are restricted to the positive integers.

The algorithm is initialized by finding the mode $\hat{\Theta}_{0}$ of the log posterior kernel, evaluated using data running from 1983:1 through 2008:4, that is, before the zero nominal interest rate episode, and $\Sigma_{\Theta}$, minus one times the inverse of the matrix of second derivatives of the $\log$ posterior kernel, evaluated at this initial maximizer. Similarly, the mode of the prior distributions for each of the duration parameters is used to initialize $\hat{\Delta}_{0}$.

A random number $n_{\theta}$ of the 16 parameters in $\Theta$ get updated in each iteration of the algorithm. First, $n_{\Theta}$ itself is chosen from a discrete uniform distribution over $[1,16]$. Next, the specific $n_{\Theta}$ parameters to be updated are randomly chosen without replacement, again from a discrete uniform distribution over $[1,16]$. Using $\Theta^{(1)}$ to denote the vector of parameters to be updated and $\Theta^{(2)}$ the vector of parameters that are not being updated, and given the previous draw $\hat{\Theta}_{i}=\left(\hat{\Theta}_{i}^{(1)}, \hat{\Theta}_{i}^{(2)}\right)$, a new proposal $\Theta_{i+1}^{(1)}$ is drawn using a multivariate Student $t$ distribution with location $\hat{\Theta}_{i}^{(1)}$, scale matrix based on a re-arrangement of $\Sigma_{\Theta}$ reflecting the partition $\Theta=\left(\Theta^{(1)}, \Theta^{(2)}\right), \nu$ degrees of freedom, and tuning parameter $\bar{\omega}$. In particular, Ding (2016) shows that if

$$
\left[\begin{array}{c}
\Theta_{i+1}^{(1)} \\
\Theta_{i+1}^{(2)}
\end{array}\right] \sim t\left(\left[\begin{array}{c}
\Theta_{i}^{(1)} \\
\Theta_{i}^{(2)}
\end{array}\right], \bar{\omega}\left[\begin{array}{cc}
\Sigma_{\Theta, 11} & \Sigma_{\Theta, 12} \\
\Sigma_{\Theta, 21} & \Sigma_{\Theta, 22}
\end{array}\right], \nu\right),
$$

then

$$
\Theta_{i+1}^{(1)} \mid \Theta_{i+1}^{(2)}=\Theta_{i}^{(2)} \sim t\left(\Theta_{i}^{(1)}, \bar{\omega}\left(\frac{\nu}{\nu+p_{2}}\right)\left(\Sigma_{\Theta, 11}-\Sigma_{\Theta, 12} \Sigma_{\Theta, 22}^{-1} \Sigma_{\Theta, 21}\right), \nu+p_{2}\right),
$$

where $p_{2}=16-n_{\theta}$ is the number of elements not being updated. 
With $\Theta_{i+1}^{(1)}$ drawn from this conditional distribution and with

$$
\omega=\min \left\{\frac{L\left(\left\{d_{t}\right\}_{t=1}^{T} \mid \Theta_{i+1}^{(1)}, \Theta_{i+1}^{(2)}, \hat{\Delta}_{i}\right) P\left(\Theta_{i+1}^{(1)}\right)}{L\left(\left\{d_{t}\right\}_{t=1}^{T} \mid \hat{\Theta}_{i}^{(1)}, \hat{\Theta}_{i}^{(2)}, \hat{\Delta}_{i}\right) P\left(\hat{\Theta}_{i}^{(1)}\right)}, 1\right\}
$$

$\varphi$ is drawn from a continuous uniform distribution on $(0,1)$. If $\varphi>\omega$, the new draw is rejected by setting $\hat{\Theta}_{i+1}=\hat{\Theta}_{i}$. If $\varphi \leq \omega$, the new draw is accepted by setting $\hat{\Theta}_{i+1}=$ $\left(\Theta_{i+1}^{(1)}, \hat{\Theta}_{i}^{(2)}\right)$. Draws for the vector of structural parameters inconsistent with the existence of a unique dynamically stable solution to the New Keynesian model during periods outside of the zero nominal interest rate episode are automatically rejected, effectively truncating the prior distribution for these parameters at the boundary of the equilibrium determinacy region. In practice, $\nu=12$ degrees of freedom is chosen for the Student $t$ proposal distribution and the tuning parameter $\bar{\omega}=0.66$ is set to achieve an acceptance rate of 0.30 for the draws of $\Theta_{i+1}^{(1)}$.

Likewise, a random number $n_{\Delta}$ of the 28 duration parameters in $\Delta$ get updated in each iteration. First, $n_{\Delta}$ is chosen from a discrete uniform distribution over $\left[1, l_{\Delta}\right]$, where $l_{\Delta} \leq 28$ is the maximum number of durations to be updated. Then, the specific $n_{\Delta}$ durations to be updated are randomly chosen without replacement from a uniform distribution over $[1,28]$, since the zero nominal interest rate episode lasted 28 quarters from 2009:1 through 2015:4.

Let $\Delta^{(1)}$ denote the vector of durations to be updated and let $\Delta^{(2)}$ be the vector of durations that are not being updated. Given the previous draw $\hat{\Delta}_{i}=\left(\hat{\Delta}_{i}^{(1)}, \hat{\Delta}_{i}^{(2)}\right)$, a new proposal $\Delta_{i+1}^{(1)}$ is drawn from a mixture $q\left(\Delta_{i+1}^{(1)}\right)$ assigning weight 0.60 to the probabilities implied by survey data used to calibrate the prior and weight 0.40 to a uniform distribution over durations ranging from one through 23 quarters. In practice, this mixture is chosen, together with a setting of $l_{\Delta}=6$, to achieve an acceptance rate of 0.27 for the draws of $\Delta_{i+1}^{(1)}$.

With $\Delta_{i+1}^{(1)}$ drawn from this distribution and with

$$
\omega=\min \left\{\frac{L\left(\left\{d_{t}\right\}_{t=1}^{T} \mid \hat{\Theta}_{i+1}, \Delta_{i+1}^{(1)}, \Delta_{i+1}^{(2)}\right) P\left(\Delta_{i+1}^{(1)}\right) q\left(\hat{\Delta}_{1}^{(1)}\right)}{L\left(\left\{d_{t}\right\}_{t=1}^{T} \mid \hat{\Theta}_{i+1}, \hat{\Delta}_{i}^{(1)}, \hat{\Delta}_{i}^{(2)}\right) P\left(\hat{\Theta}_{i}^{(1)}\right) q\left(\Delta_{i+1}^{(1)}\right)}, 1\right\},
$$

$\varphi$ is drawn from a continuous uniform distribution on $(0,1)$. If $\varphi>\omega$, the new draw is rejected by setting $\hat{\Delta}_{i+1}=\hat{\Delta}_{i}$. If $\varphi \leq \omega$, the new draw is accepted by setting $\hat{\Delta}_{i+1}=$ $\left(\Delta_{i+1}^{(1)}, \hat{\Delta}_{i}^{(2)}\right)$.

All results in the paper are based on 1 million draws taken from a simulation consisting of 11 million iterations of this algorithm. The first 1 million draws are discarded to allow for burn-in, and one out of every ten of the remaining 10 million draws are stored to generate the final results.

\subsection{Draws for the Unobservable States and Innovations}

The Metropolis-within-Gibbs algorithm described above can be extended to obtain draws for the unobservable states and innovations using the simulation-smoothing method developed by Durbin and Koopman (2002) and outlined in Durbin and Koopman (2012, pp.107-108). 
From the state-space formulation derived earlier as

$$
s_{t+1}=\nu_{t+1}+\Pi_{t+1} s_{t}+W_{t+1} \varepsilon_{t+1}
$$

and

$$
d_{t}=U_{t} s_{t},
$$

Kalman filter recursions starting from

$$
\hat{s_{1}}=0_{(14 \times 1)}
$$

and

$$
\operatorname{vec}\left(\Sigma_{1}\right)=\left[I_{(196 \times 196)}-\Pi \otimes \Pi\right]^{-1} \operatorname{vec}\left(W V W^{\prime}\right),
$$

can be used to generate recursively the sequences

$$
\begin{gathered}
v_{t}=d_{t}-U_{t} \hat{s}_{t}, \\
\Omega_{t}=U_{t} \Sigma_{t} U_{t}^{\prime}, \\
K_{t}=\Pi_{t+1} \Sigma_{t} U_{t}^{\prime} \Omega_{t}^{-1}, \\
L_{t}=\Pi_{t+1}-K_{t} U_{t}, \\
\hat{s}_{t+1}=\nu_{t+1}+\Pi_{t+1} \hat{s}_{t}+K_{t} v_{t},
\end{gathered}
$$

and

$$
\Sigma_{t+1}=W_{t+1} V W_{t+1}^{\prime}+\Pi_{t+1} \Sigma_{t} L_{t}^{\prime}
$$

for $t=1,2, \ldots, T$. From this filtering stage, the sequences for $v_{t}, \Omega_{t}$, and $K_{t}$ are stored.

Next, a value $s_{1}^{a}$ is drawn from the distribution $N\left(0_{(14 \times 1)}, \Sigma_{1}\right)$ for the initial state and a series of artificial shocks $\left\{\varepsilon_{t}\right\}_{t=1}^{T}$ drawn from $N\left(0_{(5 \times 1)}, V\right)$ for all $t=1,2, \ldots, T$. When fed through (A.21) and (A.22), these draws create an artificial data series $\left\{d_{t}^{a}\right\}_{t=1}^{T}$ that can also be run through the Kalman filter to generate sequences $v_{t}^{a}$, $\Omega_{t}^{a}$, and $K_{t}^{a}$.

For both the actual and artificial series, the terminal value $n_{T}=0_{(14 \times 1)}$ gets used to perform the backwards recursion

$$
n_{t-1}=U_{t}^{\prime} \Omega_{t}^{-1} v_{t}+L_{t}^{\prime} n_{t}
$$

where $L_{t}$ is again given by

$$
L_{t}=\Pi_{t+1}-K_{t} U_{t}
$$

yielding the sequences $\left\{n_{t}\right\}_{t=0}^{T}$ for the actual and $\left\{n_{t}^{a}\right\}_{t=0}^{T}$ for the artificial data series. These sequences are, in turn, used to generate $\left\{\tilde{\varepsilon}_{t}\right\}_{t=1}^{T+1}$ using

$$
\tilde{\varepsilon}_{t+1}=V W_{t+1}^{\prime} n_{t}
$$

and the series $\left\{\tilde{\varepsilon}_{t}^{a}\right\}_{t=1}^{T+1}$ using

$$
\tilde{\varepsilon}_{t+1}^{a}=V W_{t+1}^{\prime} n_{t}^{a} .
$$


Durbin and Koopman show that the sequence $\left\{\hat{\varepsilon}_{t}\right\}_{t=1}^{T+1}$ constructed using

$$
\hat{\varepsilon}_{t+1}=\varepsilon_{t+1}^{a}-\tilde{\varepsilon}_{t+1}^{a}+\tilde{\varepsilon}_{t+1}
$$

are draws from the posterior distribution of the vector $\left\{\varepsilon_{t}\right\}_{t=1}^{T+1}$ of innovations to the New Keynesian model's structural shocks, conditional on the entire series of observed data $\left\{d_{t}\right\}_{t=1}^{T}$.

Similarly, draws from the posterior distribution of the unobservable state vector $\left\{s_{t}\right\}_{t=1}^{T+1}$ can be taken by first drawing $s_{1}^{a}$ from the distribution $N\left(0_{(14 \times 1)}, \Sigma_{1}\right)$ and $\left\{\varepsilon_{t}^{a}\right\}_{t=1}^{T}$ from $N(0, V)$ for all $t=0,1, \ldots, T$, and using these to generate a series of artificial states $\left\{s_{t}^{a}\right\}_{t=1}^{T+1}$ using (A.21). Then, with $\left\{n_{t}\right\}_{t=0}^{T}$ and $\left\{n_{t}^{a}\right\}_{t=0}^{T}$ obtained from the backward recursions above, the sequence $\left\{\tilde{s}_{t}\right\}_{t=1}^{T+1}$ is generated from

$$
\tilde{s}_{t+1}=\nu_{t+1}+\Pi_{t+1} \tilde{s}_{t}+W_{t+1} \tilde{\varepsilon}_{t+1}
$$

starting from $\tilde{s}_{1}=\Sigma_{1} n_{0}$ and the sequence $\left\{\tilde{s}_{t}^{a}\right\}_{t=1}^{T+1}$ is generated from

$$
\tilde{s}_{t+1}^{a}=\nu_{t+1}+\Pi_{t+1} \tilde{s}_{t}^{a}+W_{t+1} \tilde{\varepsilon}_{t+1}^{a}
$$

starting from $\tilde{s}_{1}^{a}=\Sigma_{1} n_{0}^{a}$. Durbin and Koopman show that the sequence $\left\{\hat{s}_{t}\right\}_{t=1}^{T+1}$ constructed using

$$
\hat{s}_{t+1}=s_{t+1}^{a}-\tilde{s}_{t+1}^{a}+\tilde{s}_{t+1}
$$

are draws from the distribution of $\left\{s_{t}\right\}_{t=1}^{T+1}$ conditional on $\left\{d_{t}\right\}_{t=1}^{T}$.

\subsection{Additional References}

Anderson, Brian D.O. and John B. Moore. Optimal Filtering. Mineola: Dover Publications, 2005.

Binder, Michael and M. Hashem Pesaran. "Multivariate Rational Expectations Models and Macroeconometric Modelling: A Review and Some New Results." In M. Hashem Pesaran and Mike Wickens, Eds. Handbook of Applied Econometrics: Macroeconomics. Oxford: Basil Blackwell, 1995, 139-187.

Blanchard, Olivier Jean and Charles M, Kahn. "The Solution of Linear Difference Models Under Rational Expectations." Econometrica 48 (July 1980): 1305-1311.

Chib, Siddhartha and Srikanth Ramamurthy. "Tailored Randomized Block MCMC Methods with Applications to DSGE Models." Journal of Econometrics 155 (March 2010): 19-38.

Ding, Peng. "On The Conditional Distribution of the Multivariate $t$ Distribution." The American Statistician 70 (Issue 3, 2016): 293-295.

Durbin, J. and S.J. Koopman. Time Series Analysis by State Space Methods 2d Ed. Oxford: Oxford University Press, 2012.

Harvey, Andrew C. Forecasting, Structural Time Series Models and the Kalman Filter. Cambridge: Cambridge University Press, 1989. 
Higham, Nicholas J. and Hyun-Min Kim. "Numerical Analysis of a Quadratic Matrix Equation." IMA Journal of Numerical Analysis 20 (October 2000): 499-519.

Klein, Paul. "Using the Generalized Schur Form to Solve a Multivariate Linear Rational Expectations Model." Journal of Economic Dynamics and Control 24 (September 2000): $1405-1423$.

Lan, Hong and Alexander Meyer-Gohde. "Existence and Uniqueness of Perturbation Solutions to DSGE Models." SFB 649 Discussion Paper 2012-015. Berlin: Humboldt University, February 2012. 